\title{
MINERÍA, DeSCAMPESINIZACIÓN Y DESOCUPACIÓN. TRAYECTORIAS DE MoVilidad de Cuatro Mineros de El Aguilar (JuJu, ARgentina, DÉCADA DE 1940 A 2010)
}

\author{
María Parodi ${ }^{1}$ y Alejandro Benedetti ${ }^{2}$
}

\section{* Introducción}

Resumen

Desde un enfoque biográfico, se exploran las trayectorias de movilidad de cuatro mineros que trabajaron en la mina El Aguilar (provincia de Jujuy, Argentina). La actividad minera en esa provincia cobró cierta importancia, dentro del país, a raíz del despegue de esta empresa. A escala provincial, ese fenómeno conllevó migraciones, que procedieron fundamentalmente de las comunidades rurales de la región conocida como puna de Jujuy. Este trabajo, por lo tanto, se interesa por las trayectorias de migración de unidades domésticas campesinas de esta región y por las estrategias de reproducción social que fueron implementadas en las diferentes etapas del proceso migratorio. A lo largo de este trayecto, personas que se reconocían como campesinas se convirtieron en mineros y, con la crisis de la empresa hacia 1990, debieron migrar, y así, devenir en ex-mineros.

Palabras claves: minería - El Aguilar - movilidad - puna de Jujuy República Argentina.

\begin{abstract}
From a biographical approach, mobility trajectories of four miners who worked at El Aguilar mine (Jujuy, Argentina) are explored. Mining activity in that province gained some importance in the country, following the commercial success of the company. At a provincial level, this phenomenon led to migrations, mainly from the rural communities of the region known as Puna de Jujuy. This paper is therefore interested in the migration trajectories of peasant household units in the region, as well as in social reproduction strategies, which were implemented at different stages of the migration process. Throughout this journey, people who were recognized as farmers became miners, and after the crisis of 1990 had to migrate, thus becoming ex-miners.
\end{abstract}

Key words: mining - El Aguilar - mobility - Puna de Jujuy Argentine Republic.
La minería es una de las actividades productivas neurálgicas de la estructura económica de la provincia de Jujuy, Argentina, donde se produce en la actualidad el 90\% del total nacional de plata. Además, tiene una importante producción de los concentrados de plomo, zinc, cadmio, sal y boratos (Ministerio de Planificación Federal 2008). Por otra parte, el centro siderúrgico Aceros Zapla (ex Altos Hornos Zapla) produce el 90\% de las variedades de acero del país. A lo largo de la historia, de todos modos, ha tenido una importancia cambiante. Asimismo, esta actividad, en sus diferentes modalidades, ha ido definiendo buena parte de la organización territorial de la provincia, dando origen, por ejemplo, a dos concentraciones de población: la ciudad de Palpalá (Aceros Zapla) y El Aguilar (donde se encuentra la explotación homónima). A nivel provincial, la importancia de este sector se vio reflejada, también, en la creación de áreas especializadas de formación secundaria y universitaria. Esta provincia es considerada la capital de la minería en la Argentina, en tanto que la mina El Aguilar es señalada como una de las más exitosas empresas mineras del país.

La mina El Aguilar está ubicada en las tierras altas de la provincia de Jujuy (departamento de Humahuaca), y explota plomo, plata y zinc. Comenzó a funcionar a gran escala en 1936 y fue un polo de atracción para muchos trabajadores provenientes de las áreas circundantes. En 1944 , en pleno auge, empleaba a 2000 obreros. En 1980 su población era de 6800 habitantes. En 1990 comenzó una etapa de crisis y la compañía redujo drásticamente su personal. En 1991 su población se redujo a 6168; los des-

1 Instituto de Geografía, Facultad de Filosofía y Letras, Universidad de Buenos Aires. Email: lareinadelplata@hotmail.com.ar

2 Puan 470 (CP 1406) Ciudad Autónoma de Buenos Aires, República Argentina. Email: alejandrobenedetti@conicet.gov.ar 
pidos continuaron hasta mediados de esa década y miles de trabajadores y sus familias debieron migrar hacia otros destinos. Así, según el censo de 2001, la población quedó reducida a 3155 habitantes. Muchas de estas familias se instalaron en pueblos de la Quebrada de Humahuaca, como Tilcara.

La literatura que ha abordado la cuestión minera en la provincia de Jujuy es variada, aunque no muy abundante. Se pueden identificar dos grupos principales: la literatura de viajeros del siglo XIX e informes técnicos de principios del siglo XX, y los más recientes estudios sociales. La literatura de viajeros y los informes técnicos sobre la minería de las tierras altas de Jujuy es relativamente cuantiosa (Benedetti 2006; Salizzi 2014). Los abordajes desde las ciencias sociales han cobrado gran dinamismo desde mediados de la década de 1980. La cuestión de la minería no fue mayormente central en los análisis, pero dada su importancia económica para la provincia, siempre se han realizado alusiones de diferente tipo, que en general se refieren a distintos aspectos de la industria minera y las vinculaciones como trabajadores del campesinado de las tierras altas de la provincia de Jujuy. Ninguno tuvo como objetivo principal analizar la movilidad del campesinado en relación a la minería. Es un tipo de movilidad que se emparenta con aquella vinculada a la zafra, pero tiene algunas particularidades propias, ligadas a los tiempos, las formas de inserción en el mercado laboral y los intereses de los migrantes.

En función de lo anterior, este artículo tiene como objetivo reconstruir la trayectoria de migración de unidades domésticas campesinas de la puna de Jujuy y analizar las estrategias de reproducción social que implementaron en sus diferentes etapas. La investigación se realizó a partir de los relatos de vida de cuatro personas que nacieron en la puna jujeña, trabajaron como zafreros, luego fueron mineros en El Aguilar y, finalmente, se establecieron en Tilcara cuando fueron despedidos por la empresa. Se realizó un abordaje cualitativo de las trayectorias de migración de los sujetos y de las estrategias de reproducción social que pusieron en práctica en su vida cotidiana. Dentro de la riqueza que ofrece este tipo de abordaje, se optó por el enfoque biográfico. El trabajo se divide en dos partes: la primera presenta una caracterización de la historia de la industria minera en la provincia de Jujuy, y la segunda aborda las trayectorias migratorias.

\section{LA INDUSTRIA MINERA EN JUJUY}

En las tierras puneñas - ubicadas en jurisdicción de la ciudad de Jujuy - existían, desde los inicios del sistema colonial, explotaciones metalíferas como la del Espíritu Santo de Cochinoca (extracción de plata) y algunos ingenios mineros para procesar el material. En Rinconada se desarrolló, en pequeña escala, la extracción de oro de origen aluvional. Estas explotaciones atrajeron a una población apreciable, que participaba en diferentes actividades, como la construcción de ingenios, el cateo de minas o el lavado de oro. Sin embargo, durante la mayor parte de los siglos XVIII y XIX, estos yacimientos eran abandonados con frecuencia (Brackebusch 1883).

La minería, aún a comienzos del siglo XX, no era considerada un sector productivo relevante en la Argentina, ya que el proyecto nacional estaba centrado en la producción agroganadera de la pampa húmeda. En las provincias del noroeste argentino fueron los enclaves azucareros los que dinamizaron la economía; para ello, se destinaron recursos económicos a la construcción de ferrocarriles, redes viales y puertos. El mayor impedimento para el desarrollo de la industria minera, en ese entonces, eran las grandes distancias que separaban las explotaciones con respecto a los principales puertos del país. A esto se sumaba la falta de caminos hacia los yacimientos, que hacía prácticamente imposible el traslado de la maquinaria necesaria para la explotación a gran escala y el transporte de la producción hacia los centros de distribución. Además, la zona altoandina en el noroeste argentino no contaba con suficiente cantidad de mano de obra, lo cual suponía la necesidad de implementar políticas migratorias. Por último, los cuadros técnicos eran escasos (Benedetti 2005).

El Estado nacional había enviado varias expediciones a la región con el objeto de conocer sus potencialidades productivas. Diferentes informes sobre Jujuy o el Territorio Nacional de Los Andes, publicados por el Ministerio de Agricultura, hablaban principalmente de la riqueza de boratos existentes en las tierras altoandinas, aunque durante la primera mitad del siglo XX se mantuvieron en una situación de inacción casi total (Benedetti 2006). La población indígena de la región se dedicaba centralmente al pastoreo (ovejas, llamas y cabras) y existían muy pocos trabajadores especializados en la labor minera. Una acti- 
vidad vinculada a la minería era la extracción de panes de sal de las salinas, para intercambio por productos en las zonas lindantes; pero ésta no suponía un nivel importante de especialización en los quehaceres mineros y poseía una baja incidencia en la economía campesina (Cipolletti 1984). En suma, hasta las primeras décadas del siglo XX, la minería constituía una actividad secundaria. La explotación minera más importante en la puna jujeña, en la década de 1930, era controlada por la empresa norteamericana National Lead Company, productora de plomo en los yacimientos de Pumahuasi, Sol de Mayo, La Bélgica, La Pulpera y Cangrejillos.

A partir de entonces, comenzó a establecerse lentamente la gran minería, acompañando el proceso de industrialización del país y el consecuente surgimiento de las primeras fábricas metalúrgicas, de aleaciones y las industrias básicas. En 1933 se constituyó la firma Pirquitas, Picchetti y Cía. para explotar un rico yacimiento de plomo y plata en el departamento de Rinconada (Teruel 2006). El Aguilar era otro yacimiento importante en la zona, donde se podía extraer plomo, zinc y plata. Está ubicado en el departamento de Humahuaca, entre los 4000 y $4500 \mathrm{msnm}$, a $247 \mathrm{~km}$ por ruta desde San Salvador de Jujuy, capital provincial. Este yacimiento comenzó a ser explotado en 1936 por Compañía Minera Aguilar, subsidiaria de la norteamericana St. Joseph Lead $C^{\circ}$. El Aguilar logró un alto grado de mecanización en la extracción de mineral con la incorporación de tecnología moderna. Por primera vez en la provincia, se instaló la técnica de flotación para separar los minerales de zinc y plomo, obteniendo concentrados de alto rendimiento (Teruel 2006). La actividad llevada a cabo en esta mina generó el desarrollo del asentamiento minero homónimo, virtualmente, una nueva ciudad que llegó a contar con policía, Registro Civil, cuatro escuelas provinciales, dos escuelas profesionales para mujeres, dos jardines de infantes, un hospital y dos estadios cubiertos climatizados en donde se llevaban a cabo prácticas deportivas y proyección de películas. De este modo, se convirtió en un centro de migración para los campesinos de las zonas aledañas, que pasaban a residir en forma permanente en el centro minero. En 1944, empleaba aproximadamente a 2000 obreros (Kindgard 1987).

Entre 1914 y 1947 se produjo el aumento demográfico más importante del siglo en las tierras altas de Jujuy, en parti- cular en los departamentos de Rinconada, Humahuaca y Yavi. La minería y el desarrollo de la ciudad de La Quiaca, terminal del ferrocarril e importante centro comercial en la frontera con Bolivia, fueron las principales causas de este crecimiento demográfico (Benedetti 2015). Así, fue cambiando el eje demográfico regional desde las aguadas y los rincones de reparo del viento, hacia la árida planicie central (Gil Montero 2006). Esto coincidió con un fuerte flujo migratorio de los hombres - especialmente entre 1950 y 1980 - para trabajar en las cosechas de caña en las tierras bajas, en la de tabaco en Salta y Jujuy y, más tarde, en la de la fruta de carozo en Mendoza. En 1943 se inauguró la planta industrial de Altos Hornos Zapla, en la localidad de Palpalá, que también atrajo una cantidad considerable de hombres. Durante la Segunda Guerra Mundial aumentó la demanda de metales básicos como los que se extraían en El Aguilar, lo cual aumentó el nivel de producción y exportación y, en consecuencia, la cantidad de obreros empleados. La participación del sector minero en la estructura económica de Jujuy fue creciendo sostenidamente entre la década de 1960 y el fin de la década de 1970. Es de notar que, en buena medida, este hecho se debió a Altos Hornos Zapla. En 1975, esta empresa aumentó considerablemente su producción de acero con la puesta en funcionamiento del que sería el último alto horno. En 1977 se decretó la Ley de Promoción Industrial de la Provincia. En concordancia con la política nacional de reemplazo del modelo de industrialización sustitutivo, el gobierno de la provincia de Jujuy (en ese momento, de facto) posibilitó el acceso al crédito a las empresas ya existentes. Altos Hornos Zapla terminó entonces el tren fino de laminación, Mina Aguilar realizó también importantes ampliaciones, y se instaló en la zona de Rinconada la Compañía Minera Pan de Azúcar (Teruel 2006).

A principios de la década de 1980, la minería era considerada como uno de los recursos con mejores potencialidades de la provincia que, incluso, había motivado la creación de centros de formación técnica y profesional en la especialidad: Escuela de Minas y carrera de ingeniería en minas, dentro de la Universidad Nacional de Jujuy. A mediados de la misma década, sin embargo, con excepción de las empresas con grandes capitales, el resto de las explotaciones mineras estaban al borde de la quiebra. A través de convenios, la provincia de Jujuy se sumaba a los planes del gobierno central para reactivar la minería. Altos Hornos Zapla se encontraba en estado de produc- 
ción mínima, con racionalización de gastos y reducción de la planta de personal (Fleitas y Kindgard 2006; Teruel 2006). Mina Pirquitas, que producía estaño y plata, vio reducidas sus ventas por la importación de estaño de Brasil a precios inferiores. Esta compañía adeudaba varios meses del salario de los mineros, a quienes sometía a duras condiciones laborales. La crisis se agravó con la caída abrupta de los precios internacionales del estaño, y esta empresa se declaró en quiebra a principios de 1990 (Fleitas y Kindgard 2006). Luego, fue adquirida —en remate por quiebra - por la compañía Sunshine Argentina S.A. Los obreros despedidos durante este proceso protagonizaron los primeros "piquetes" (cortes de ruta como protesta) de la provincia de Jujuy, y originaron importantes movimientos sociales.

Durante la década de 1990 se produjo en Argentina la profundización del modelo económico neoliberal, que implementó políticas de ajuste. La reforma del sector público, el proceso de privatizaciones, la apertura de los mercados, el fin de los precios fijos y la entrada de empresas trasnacionales que comenzaron a competir, significaron una reconversión productiva del sector privado. En este nuevo marco de concentración económica, contracción del Estado y cese de sus funciones redistributivas, las modificaciones del mercado de trabajo en términos de precarización y desempleo se vieron también presentes en la provincia de Jujuy, alcanzando a la actividad minera. Al igual que en el resto del país, en Jujuy aumentó la desocupación y se redujeron los empleos permanentes con protección social, que fueron reemplazados por empleos transitorios, sin beneficios sociales en la mayoría de los casos (Panaia y Aparicio 2000). Durante este período se derogaron las disposiciones que dificultaban o impedían el acceso del capital externo a la minería. El Aguilar era, en ese momento, el mayor productor nacional de plomo, plata y zinc. Sin embargo, debido a los gravámenes impuestos desde el Estado nacional, la empresa tenía dificultades para exportar. Su producción de baritina estaba, además, prácticamente paralizada. La caída de los precios internacionales de los minerales que explotaba agravó la situación. Sumado a lo anterior, en 1993, al trabajar el yacimiento a mayor profundidad, surgió un inconveniente adicional: se encontró manganeso, mineral que redujo la competitividad de los concentrados. Por aquel entonces, el complejo fue adquirido por el grupo norteamericano COMSUR, que operaba en Bolivia. Se redujo un 30\% la producción de la mina, a la vez que la cantidad de operarios bajó drásticamente de 1800 (entre técnicos, obreros y empleados administrativos) a solo 598 . Una privatización, con un altísimo impacto simbólico por ser el emblema de industrialización de la provincia, fue la de Altos Hornos Zapla. Con la formación de la nueva empresa, Aceros Zapla, se redujeron alrededor de 2000 puestos de trabajo, de un total de 2560 , durante el primer año. Esto, sumado a la situación de desempleo general, tuvo graves consecuencias sociales para la provincia (Teruel 2006).

En el resto de la provincia de Jujuy, las privatizaciones, el cierre del ramal ferroviario a La Quiaca y la reestructuración del área minera, también generaron inmediatamente desempleo. De las 2017 personas ocupadas en la minería en 1991, en 1995 quedaban 754, distribuidas en 16 empresas dedicadas a la explotación de boratos, sal y caliza (Teruel 2006). Fue entonces que los mineros entrevistados durante la realización de esta investigación fueron despedidos de la mina El Aguilar y migraron hacia la Quebrada de Humahuaca.

A la par de la crisis minera y la reducción constante de la demanda de trabajadores temporarios en la zafra azucarera, se produjo el congelamiento de la planta de trabajadores del estado (Kindgard 2001). En efecto, si se observa la evolución de la tasa de desocupación de la provincia a partir del año 1989, se notará que los valores aumentan, llegando en 1997 a superar el doble de los valores de fines de la década de 1980. La evolución de la tasa de actividad de la provincia prácticamente no se modificó. La economía jujeña fue incapaz de incorporar nuevas personas al mercado laboral, produciendo un aumento en el trabajo por cuenta propia, la generación de microemprendimientos de éxito variable y el fin de la inserción laboral estable para muchísimas familias jujeñas.

\section{CUATRO EXPERIENCIAS DE VIDA EN TORNO A EL AGUILAR}

En esta parte se analizarán las estrategias de reproducción social de un determinado grupo humano, siguiendo su trayectoria migratoria a través de cuatro historias de vida. Se trata de personas que, siendo niños, vivieron en las tierras altoandinas de la provincia de Jujuy, desarrollando el pastoreo, mientras sus padres debían migrar en forma temporaria a la zafra de los enclaves azucareros 
de las tierras bajas. Luego, fueron ellos quienes debieron hacer esto mismo, en las décadas de 1950 y 1960 . Paralelamente, se fueron insertando en el enclave minero El Aguilar, hasta 1990, cuando fueron despedidos de su trabajo. Desde allí migraron hacia Tilcara, en la Quebrada de Humahuaca, de la misma provincia. Estas trayectorias fueron reconstruidas a través de entrevistas realizadas a los propios sujetos.

Los cuatro relatos se presentarán ordenados por tres ejes paralelos que los relacionan entre sí: un eje cronológico, un eje espacial y un eje conceptual (Cuadro 1). Además, en cada uno se resaltará algún aspecto en particular, que se repite en los otros tres casos, por resultar todos representativos de la experiencia de vida de un grupo humano más extenso al que pertenecen. Se presentarán también cuatro mapas (Figuras 1 a 4), uno para cada relato, que representarán en forma gráfica cuatro momentos migratorios diferentes en las vidas de los sujetos. Se detallarán solo las movilidades que resultan centrales dentro de las estrategias de reproducción social de la unidad doméstica.

\section{La comunidad de origen y la vida campesina}

Cecilio nació en 1946 en Miyuyoc, una pequeña localidad que se encuentra en el departamento de Humahuaca, provincia de Jujuy, en el borde oriental del sector argentino de las tierras altoandinas. En 1995, este poblado contaba con 98 personas distribuidas en 27 unidades de producción campesinas ${ }^{3}$ (Pagliaro 1995). Las casas de Miyuyoc están dispuestas a la vera de un camino de ripio que sirve de acceso al poblado y que, ocho kilómetros más al sur, se empalma con el camino que une Humahuaca con Iruya. Cecilio cuenta lo difícil que resultaba salir a Iturbe, donde se realizaban las compras. Se hacía generalmente a pie y eran necesarios los burros cuando se trataba de llevar productos al mercado de Iturbe o traer mercadería desde allí. En la actualidad, debido al auge de
Iruya como destino turístico, el camino principal ha sido mejorado y el tránsito es constante. Sin embargo, aún hoy Miyuyoc continúa siendo un lugar de difícil acceso y con un grado importante de aislamiento en comparación con los poblados más cercanos al camino principal. La parte más nutrida de construcciones se ubica alrededor del edificio de la escuela, que funciona como núcleo articulador. Al lado de la escuela se encuentra el puesto sanitario y la capilla. Cuando Cecilio era niño, ya funcionaba en el poblado esta escuela pública, a la que asistió hasta segundo grado. Allí también estudiaron algunos de sus hermanos. Las hermanas ayudaban a su madre en la casa y no concurrieron a la escuela.

Las casas están construidas con paredes de adobe y techos bajos con caña y torta de barro. Algunas del núcleo principal del pueblo poseen techos de chapa, puertas y ventanas de carpintería, notándose en ellas la influencia de una arquitectura más citadina. Como en muchos otros lugares de las tierras altas de Jujuy, las casas suelen distribuirse en torno a un patio cerrado. Se trata de una serie de estructuras e instalaciones que sirven a variados usos.

3 En este artículo se utilizará el término campesino para hacer referencia a los hombres y mujeres rurales cuyas trayectorias de migración se analizan aquí. No es el fin debatir sobre la cuestión campesina en general, sino caracterizar a los sujetos que, en su origen y trayectoria, pueden identificarse como tales. Debido a que son múltiples las conceptualizaciones que se han elaborado para abordar la condición campesina, se rescatarán aquellos rasgos que resultan más significativos para su caracterización. Las comunidades campesinas de las que forman parte estos pequeños productores en origen son: unidades sociales de trabajo y producción que poseen una subsistencia de base agropastoril, y que bajo cualquier régimen de tenencia, producen para el autoconsumo y eventualmente para el mercado, en condiciones de escasez de recursos naturales (tierra y/o agua); la mano de obra es predominantemente familiar; hay limitada o nula capitalización de la unidad productiva.

\begin{tabular}{|c|c|c|c|c|}
\hline & Cecilio & Santiago & Ceferino & Mariano \\
\hline Eje espacial & La comunidad puneña de Miyuyoc & Entre Chaupi Rodeo y los ingenios & Mina El Aguilar & De mina El Aguilar a Tilcara \\
\hline $\begin{array}{c}\text { Eje temporal } \\
\text { (aprox.) }\end{array}$ & La vida campesina (1940-1960) & $\begin{array}{c}\text { La partida hacia la zafra (1960- } \\
1970)\end{array}$ & $\begin{array}{c}\text { La llegada y el trabajo minero } \\
\text { (1970-1990) }\end{array}$ & $\begin{array}{c}\text { La llegada y la vida en Tilcara } \\
\text { (1990-2010) }\end{array}$ \\
\hline Eje conceptual & $\begin{array}{c}\text { Las estrategias de reproducción } \\
\text { campesina }\end{array}$ & $\begin{array}{c}\text { La migración temporal como } \\
\text { estrategia }\end{array}$ & $\begin{array}{c}\text { Las estrategias de } \\
\text { matrimonio y de educación. }\end{array}$ & Las nuevas estrategias \\
\hline
\end{tabular}

Cuadro 1. Ejes que se abordarán en cada relato. Nota: respetando el pedido de uno de ellos, se han cambiado sus nombres y no se mencionan los apellidos. 


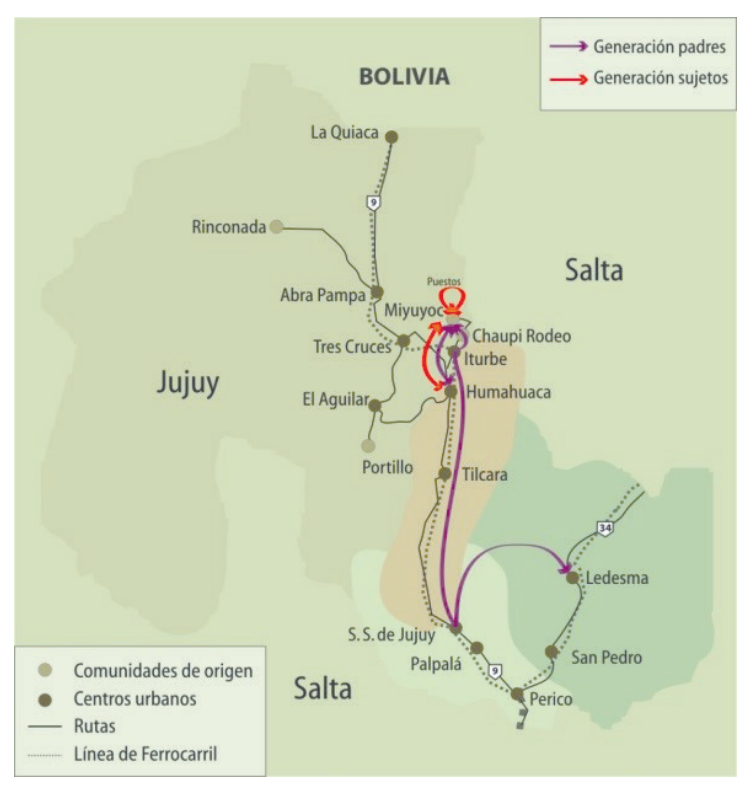

Figura 1. Movilidad durante la etapa de reproducción campesina (1940-1960).

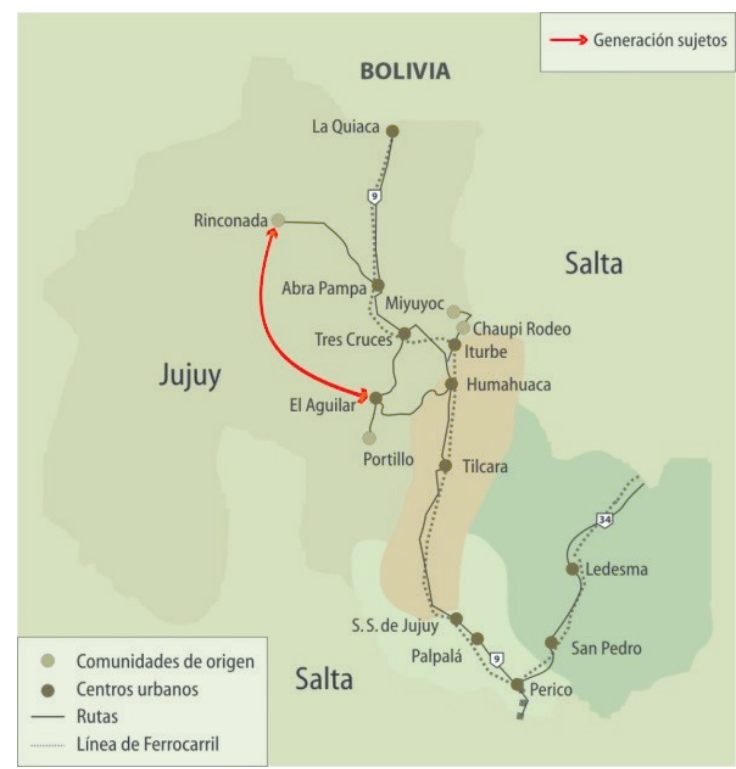

Figura 3. Movilidad durante la etapa de reproducción en la mina (1970-1990).

Las ventanas son casi inexistentes $y$, cuando las hay, son sumamente pequeñas para mantener la temperatura en el interior. Las puertas más antiguas son de madera de cardón pero, con el tiempo, se fueron reemplazando por puertas de otras maderas o de chapa. En verano se cocina en el patio desde temprano. En el invierno, que puede ser sumamente frío, se cocina dentro, en un fogón. Muchas

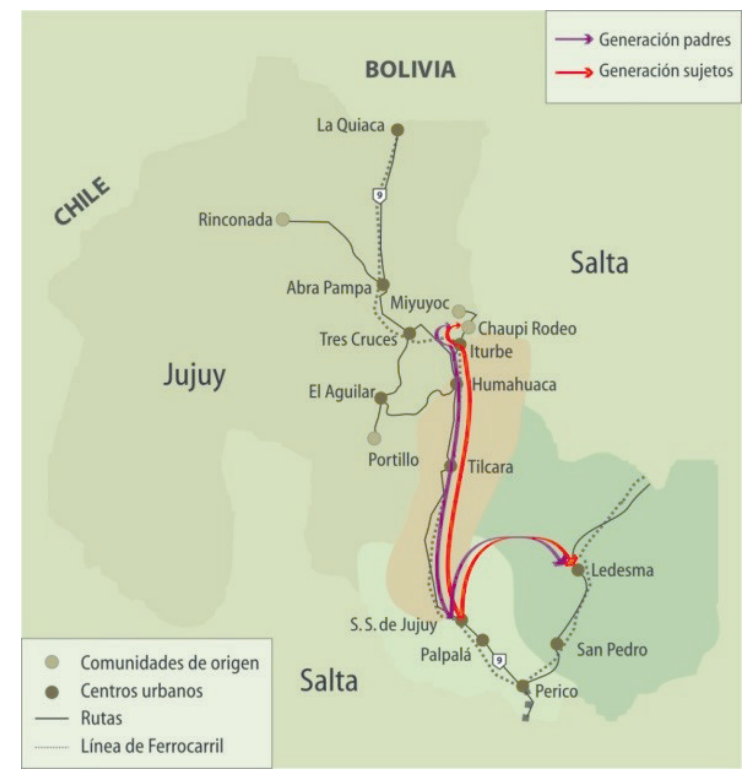

Figura 2. Movilidad durante la etapa de reproducción en la zafra (1960-1970).

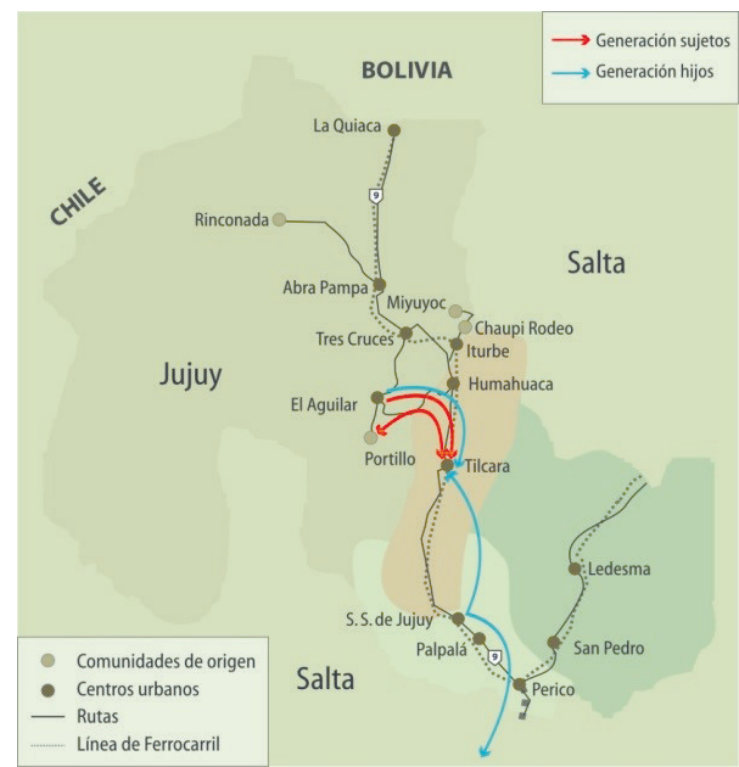

Figura 4. Movilidad durante la etapa de reproducción como ex-mineros (1990-2010).

casas cuentan con un horno de barro para el pan. Los cueros de oveja cubren bancos de madera, sillas y colchones. Algunas de las piezas funcionan de depósito, donde se guarda la mercadería, la carne, los vellones de lana y las herramientas. En un lugar protegido de la casa siempre se encuentra un pequeño altarcito con figuras y estampas de los santos "de la gente" y "del ganado" (como San 
Bartolo, santo de las cabras, o San Juan, santo de las ovejas). Allí se reserva un lugar especial para Santa Bárbara, patrona de Miyuyoc.

Los miembros de la unidad doméstica duermen en uno o dos dormitorios. Además, la mayor parte de las casas cuenta con una habitación más, la "ramada", destinada a las visitas o a la celebración del día de las almas. Las casas que seencuentran un poco más retiradas del núcleo principal cuentan con corrales para las ovejas y cabras y otros para los burros, aunque estos pastan libremente por los alrededores. Asimismo, existen algunas parcelas de cultivo rodeadas por pircas de piedra que resguardan los cultivos del viento y de los animales. Cada unidad doméstica usufructúa ciertas tierras de pastoreo y fuentes de agua para los hombres y el ganado. Además, existen pastoreos y aguadas comunitarias. A distancias variables, de hasta dos días de caminata, se encuentran los "puestos", llamados "estancias" en otros lugares de la región (Tomasi 2005). Estos puestos consisten principalmente en corrales para el ganado y construcciones pequeñas, muchas veces sin techo, que sirven de refugio contra el viento y la lluvia. Cada unidad doméstica tiene diferente cantidad de puestos, según el tamaño y la humedad de la tierra que ocupa, la cantidad de ganado que posee y la disponibilidad de mano de obra. Los puestos a donde se lleva a pastorear las ovejas varían según la estación del año: la "veranada" se realiza más cerca de la casa, en tierras más bajas, y la "invernada" en puestos de altura, en época de seca, cuando el agua se retrae hacia las nacientes.

La unidad doméstica era la arena central de producción, distribución, consumo y reproducción social. La mayoría de ellas estaban compuestas por tres generaciones (padre y/o madre, hijos e hijas, hijos de hijas). Las familias de los cuatro entrevistados tenían un promedio de 11 personas en esa etapa de sus vidas; $y$ las cuatro se encontraban en proceso de expansión. La relación entre productores y consumidores era bastante pareja y ninguna unidad contrataba mano de obra externa a la familia para trabajar en el predio. En la totalidad de las familias convivían ambos padres; en dos casos convivían con otros parientes. Estudios de las unidades domésticas de otros sectores de la puna (Göbel 2002) dan cuenta de que la matrifocalidad es una constante en la organización social. Según su análisis de la comunidad de Huancar, el 37\% de los hogares tiene a una mujer soltera como jefa de familia en la actua- lidad, y este tipo de organización social se remontaría por lo menos a un siglo atrás. En ninguna de las cuatro unidades domésticas analizadas aquí se daba este fenómeno, ya que en todas convivían el padre y la madre. Dentro de la categoría hijos e hijas, los entrevistados incluyen a niños adoptados (dos en total); los "criados", que pueden ser hijos de algún pariente que no tiene los medios para criarlos, o bien, niños huérfanos de ambos padres o de uno de ellos que son acogidos en otra familia. Ésta es una práctica extendida en las tierras altas de Jujuy. En la familia de origen de Cecilio no había hermanos adoptados.

La principal actividad económica de la puna ha sido históricamente el pastoreo itinerante, que varía según regiones. El tipo y cantidad de ganado que posee cada unidad doméstica fluctúa según las condiciones ecológicas de cada lugar entre ovejas, cabras, llamas y, en algunos sitios, algunas vacas. Los burros no son considerados como parte del "ganado" o la "hacienda" en los relatos de los propios productores, aunque sí en los relatos elaborados por personas externas a la comunidad. Los productos provenientes de esta actividad se utilizaban casi en su totalidad para el autoconsumo o para abastecerse, mediante el trueque o venta, de otros productos que no se producen en la zona: coca, ají, maderas, maíz, frutas, etc. El ganado doméstico se emplea para el consumo de carne (fresca o como charqui) y, ocasionalmente, se vende. También se extrae lana de las ovejas y las llamas, los burros se utilizan para el transporte de productos, el guano de llama se emplea como combustible y los cueros se destinan a la confección de mantas donde acostarse o para la fabricación de instrumentos. La leche de las cabras se consume o se transforma en quesos (Göbel 2002, Gil Montero 2006).

Se puede describir a la familia de origen de Cecilio $-\mathrm{y}$ a las de los otros tres entrevistados - como campesina, en los términos aquí propuestos. Su subsistencia se basaba en la actividad agropastoril. Si bien no poseía títulos formales de propiedad, ejercía el dominio efectivo sobre la tierra que cultivaba. El ganado era el principal capital que distribuían a los hijos al momento de casarse para que pudieran comenzar una vida independiente. Existía una relación afectiva cercana con la hacienda: llamas, ovejas y cabras eran percibidos como miembros no humanos de la unidad doméstica. La familia cultivaba habas, papas y arvejas en las tierras de Miyuyoc. Al igual que en las otras 
tres unidades domésticas, la mano de obra utilizada, tanto para el cultivo como para el pastoreo, era familiar y no se contrataban personas en ningún momento del ciclo productivo. Las dificultades planteadas por la falta de infraestructura de riego, en una región árida, y el bajo nivel de tecnología con la que contaban las familias, restringía el tamaño y la variedad de la explotación. La producción se realizaba para el autoconsumo, y solo ocasionalmente se destinaba una pequeña parte para trueque o venta en las localidades vecinas. El dinero obtenido se destinaba a la compra de bienes necesarios que no se producían, como las herramientas.

El objetivo económico y social básico de estos productores es asegurar la subsistencia y reproducción de su grupo. Para ello, se plantean una estrategia basada en la "multiocupación": usualmente son, a la vez, productores agrícolas, criadores de ganado, recolectores de productos naturales (yuyos o panes de sal), artesanos (sogas o tejido) y, además, trabajadores asalariados, ya sea en el lugar donde viven o como migrantes temporarios a otros lugares. El común denominador de todas las unidades domésticas en estudio fue la imposibilidad de alcanzar el nivel de reproducción campesina simple con el desarrollo de sus prácticas agropastoriles tradicionales. Este hecho provocó la necesidad buscar trabajo asalariado. En el discurso de los entrevistados, solo el trabajo extrapredial a cambio de un salario era considerado "trabajo", no tanto así el que se llevaba a cabo en la localidad de origen, que era desempeñada básicamente por las mujeres. En la mirada de estos hombres, las mujeres, entonces, no trabajan. La no presencia temporaria de los hombres de la unidad doméstica es una imagen recurrente en los relatos de vida. Esta presencia-ausencia de los hombres generó procesos de reacomodamiento en la economía pastoril, por ejemplo, en las relaciones de género y en el manejo de los rebaños. Durante el invierno las mujeres realizaban tareas tradicionalmente a cargo de los hombres como, por ejemplo, el tejido en telar. El pago por el trabajo temporario en la zafra azucarera se invertía en productos básicos como azúcar, polenta, frangollo, harina y algunos productos de lujo (muebles, bicicletas o radios). También estaba destinado a pagar las deudas con la proveeduría de Iturbe, que se iban acumulando a lo largo del invierno.

Existía, y existe en la economía agropastoril de Miyuyoc y de las otras tres localidades, una marcada división del trabajo por género. Las mujeres eran las encargadas del cuidado diario de la hacienda, auxiliadas por los niños. Se ocupaban de las tareas domésticas como cocinar, lavar la ropa, limpiar, etc. Además, trabajaban a la par de los hombres en la época de siembra y de cosecha. Los hombres intervenían en este cuidado para algunas tareas especiales que requerían de mayor fuerza física como, por ejemplo, la esquila, la castración, la señalada o la reparación de los corrales. Los hombres también tejían con agujas o en telar, frazadas, mantas, telas, tanto para el uso doméstico como para el intercambio. Araban la tierra, sembraban y realizaban tareas de mantenimiento; pero su rol económico principal era articular la economía local con el "mundo exterior" (Benedetti 2001). Esto se hacía realidad tanto con la migración temporal como con las salidas a otros pueblos a realizar trueques para aprovisionarse.

Una de las características de los campesinos de estas tierras es que poseen una red de relaciones con otros campesinos, que se extiende mucho más allá de su lugar de residencia. Desde este punto de vista, no son personas aisladas, aunque lo parezcan. Sin embargo, a diferencia de lo que sucede en otras zonas de los Andes, aquí se han perdido en gran medida los sentimientos de pertenencia comunitaria y organización colectiva que daban, a la vez, seguridad e identidad. Algunas trazas que han quedado de ello son, por ejemplo, el trabajo común en las obras de riego, algunos trabajos recíprocos (la minga) y los ritos y fiestas comunitarios (Reboratti 1998; Göbel 2002). La identificación de pertenencia más fuerte es con la unidad doméstica y el lugar físico en donde ésta se ubica. El día del santo patrono del pueblo se llevan los misachicos (las imágenes que cada unidad doméstica tiene) a la capilla, al son del canto y los sikus, donde son bendecidos. La principal festividad en Miyuyoc es el cuatro de diciembre (Santa Bárbara).

La infancia y primeros años de la adolescencia de Cecilio, Ceferino, Santiago y Mariano se desenvolvieron en el medio rural de la puna de Jujuy, entre 1945 y 1960 , aproximadamente. Allí fueron pastores y agricultores. La producción la destinaban casi exclusivamente para el autoconsumo, y el escaso excedente lo intercambiaban por bienes que no poseían. Sus padres alternaban el trabajo predial durante el verano con las migraciones temporales a la zafra azucarera en los largos meses del invierno. La 
movilidad del resto de los miembros de la familia se reducía al ámbito de la casa, el pueblo y los puestos donde llevaban a pastorear el ganado. Ocasionalmente, esa movilidad incluía viajes de intercambio a pueblos de mayor tamaño. La educación formal no era vista como prioritaria. Los jóvenes varones permanecían en el ámbito de la unidad doméstica hasta alcanzar entre 13 y 15 años, la edad necesaria para poder "salir a trabajar". El siguiente relato se centrará en esta salida hacia la zafra azucarera.

\section{El mundo de la zafra y las migraciones temporales}

La familia de origen de Santiago es de la localidad de Chaupi Rodeo, cercana a Miyuyoc. Ambas, como así también las de los restantes entrevistados, se encontraban subsumidas a la dinámica del capitalismo regional azucarero, como proveedoras de mano de obra estacional.

Entre 1960 y 1970, la composición de las cuatro familias no difería demasiado de la descrita en el apartado anterior. Lo que sí había variado era la cantidad de integrantes en edad de incorporarse al mercado de trabajo como mano de obra estacional. A la vez, los miembros que antes eran demasiado pequeños para ocuparse de las tareas domésticas, ahora reemplazaban a aquellos que se movilizaban hacia la zafra, por lo que no cambiaba demasiado la dinámica de la unidad doméstica. La localidad de origen de Santiago, al igual que la de los otros tres sujetos, era agropastoril de muy baja productividad, inserta en una estructura agraria minifundista. Existían tres variantes de minifundios en esta región: de subsistencia, ganadero y de cultivo comercial (Reboratti 1983). El primero consiste en pequeños predios cultivados con maíz, habas, papas y otros productos de autoconsumo, que se complementan con la tenencia de pequeñas cantidades de ovinos o caprinos en pasturas comunales. En esta variante se incluían las familias de Santiago, Cecilio y Mariano. El minifundio ganadero era típico de la zona puneña, con reducida aptitud natural para la producción agrícola, y se basa en la tenencia de reducidos rebaños de ovinos y llamas, que pastan en grandes extensiones de tierras fiscales. En esta variante encontramos a la familia de Ceferino. Finalmente, había minifundios comerciales, de los que no hay representantes en este trabajo, basado en la producción que se comercializaba localmente. A diferencia de otro tipo de explotación, las unidades domésticas involucradas en este estudio no podían contratar mano de obra para reemplazar la mano de obra ausente. Debido a esto, la estrategia elegida para el trabajo asalariado era forzosamente estacional, lo que les permitía complementar los pequeños rendimientos obtenidos de los cultivos del verano, con el trabajo asalariado como cosecheros en los ingenios durante el invierno. Esta estacionalidad del trabajo asalariado en los ingenios le ahorra al capital el costo de su reproducción durante la estación muerta y le genera ganancias extraordinarias (Meillasoux 1985). El hecho de que parte de su reproducción esté a cargo de la unidad doméstica, le permite al capital el pago de salarios bajos -incluso por debajo del costo de la reposición de la mano de obra vendida-, que no serían tolerados por trabajadores totalmente proletarizados que dependen exclusivamente de su salario para subsistir. Otra forma de extracción de excedentes es a través de la prolongación sistemática de la jornada laboral, o sea, a través de la extracción de la plusvalía absoluta (Gordillo 1995).

La forma de articulación de las zonas emisoras de mano de obra con la zona receptora (la industria azucarera) fue cambiando a través del tiempo y según la región. Hasta 1930, la mayor parte de la mano de obra estaba integrada por personas de los grupos étnicos toba y mataco, provenientes de la región chaqueña. La coacción extraeconómica, y el apoyo del ejército y de la Iglesia anglicana (Trinchero 2000), fueron predominantes para la localización y el conchabo de los indígenas. Luego, comenzaron a contratar cada vez mayor cantidad de mano de obra de otras regiones, entre ellas la puna jujeña, de donde provienen las cuatro unidades domésticas estudiadas. Los puneños presentaban la ventaja de que, al ser agricultores, eran más hábiles para cortar y cargar la caña. Tenían casi nula experiencia gremial y era poco probable que iniciaran protestas laborales, al menos inicialmente. A esto se sumaba el hecho de que eran más dóciles y no reñían entre ellos tanto como lo hacían los chaqueños, según los informes de los capataces (Whiteford 1981).

Una modalidad de reclutamiento fue la de comprar o arrendar grandes fincas y obligar a los hombres del lugar a trabajar en las plantaciones como forma de pagar su derecho a la tierra. Sumado a esto, los campesinos se veían materialmente imposibilitados de emprender actividades productivas más favorables. Este proceso llevó a un estado de pobreza y de creciente dependencia del ingreso extrapredial, generando la proletarización parcial que 
aún hoy persiste. Si bien en 1949, durante el gobierno de Juan Perón, se expropiaron las haciendas de la puna y la Quebrada de Humahuaca, poniendo fin al sistema de pago de renta en trabajo, los campesinos continuaron asistiendo a la zafra en forma cuasi voluntaria (Rutledge 1987). Los contratistas fueron actores importantes en la articulación entre los ingenios y las zonas proveedoras de mano de obra estacional. En muchos casos eran personas reconocidas del pueblo: un comerciante, un empleado municipal o incluso un maestro. Estas personas actuaban a cuenta propia o por cuenta del ingenio y reclutaban a los trabajadores. El hecho de ser local les daba ventajas frente a otros contratistas, por el hecho de conocer personalmente a los hombres y saber con anticipación su disponibilidad o no para contratarse. Santiago y su familia eran contratados por un contratista de la localidad de Iturbe. En este centro de reclutamiento se encontraba la estación en la cual subían al tren los trabajadores del área ubicada al noreste de Humahuaca que los llevaban al ingenio. Otras veces, el contratista era alguien llegado de otras regiones que contaba con información sobre la demanda de mano de obra en los ingenios. Reunía cuadrillas de trabajadores, les retiraba el documento para reforzar el compromiso a presentarse, y acompañaba al contingente hasta la plantación. Allí, era él quien negociaba las condiciones de trabajo de los hombres de sus cuadrillas. A cambio de cada documento de identidad, cobraba un importe al ingenio (Whiteford 1981).

En el momento en que Santiago participó de la zafra, existían cuatro ingenios en Jujuy —-Ledesma, con 44\% de la producción de ambas provincias, La Esperanza, con el 16\%, y Río Grande, con el 11\% - y dos en Salta — San Martín del Tabacal, con el 25\%, y San Isidro, con el 4\% (Bisio y Forni 1976) - Santiago trabajó en tres de ellos durante los ocho años en que fue zafrero. Informa que el primer cambio de destino fue en 1965 , cuando su padre, debido a un accidente de trabajo, no pudo seguir concurriendo a la zafra y el vínculo con el contratista original se disolvió. Santiago se presentó en el ingenio San Martín por cuenta propia y trabajó allí en tres campañas. Luego de "hacerse conocido" por el capataz como trabajador responsable, acordaba de una campaña a la siguiente. El último año que participó en una zafra fue 1968, en San Isidro.

Los cuatro entrevistados decidieron esperar tener edad suficiente para conseguir un trabajo en la mina - lo cual era considerado un trabajo estable - antes de formar una familia propia. Un dato que se repite como razón de peso para la adopción de esta estrategia matrimonial es la precariedad de las viviendas en la zafra y el clima agobiante que generaba enfermedades, en oposición a las comodidades que, en este aspecto, ofrecía el trabajo en El Aguilar. El trabajo en la zafra era considerado momentáneo, servía para contar con un ingreso extrapredial hasta alcanzar la edad mínima de ingreso a la mina. En ingenios azucareros los accidentes eran frecuentes, y la mortalidad infantil, alta. Surge aquí, con claridad, la diferencia entre el trabajador temporario clásico y el trabajador temporal transitorio. En la primera categoría puede incluirse a la generación de los padres de los entrevistados, mientras que ellos pueden considerarse dentro de la segunda categoría. El acceso a la educación formal para sus hijos no fue expuesto en ninguna de las entrevistas como razón para optar por uno u otro lugar de trabajo. Si bien existía una escuela en el ingenio, eran pocos los hijos de zafreros que concurrían regularmente a la misma, ya que eran empleados para ayudar a sus padres en la cosecha.

En la década de 1960, durante la cual Santiago, Cecilio, Ceferino y Mariano migraron a la zafra (entre los 15 y los 20 años, en promedio), los sindicatos del surco tenían poca influencia sobre los trabajadores estacionales. En primer lugar, el ingenio despedía o no recontrataba a los trabajadores que se quejaban o alteraban el orden establecido de alguna manera, lo cual privaba a los cosecheros de los líderes naturales que pudiesen surgir. Además, la dinámica propia de la zafra dejaba poco espacio para los encuentros sociales o gremiales, ya que los trabajadores terminaban el día agotados y buscaban acostarse temprano para aprovechar el día siguiente. Por estatuto, estaba prohibido que los trabajadores estacionales ocuparan puestos en el sindicato, y no tenían ni voz ni voto en el gremio a pesar de que se les descontaba la cuota puntualmente. Los trabajadores permanentes, en cambio, tenían injerencia en los reclamos y las decisiones del gremio, por lo que eran sus propios reclamos, y no los de los obreros estacionales, los que eran atendidos por el sindicato. Debido a su alta dependencia del salario y la ausencia de poder sobre las decisiones, los obreros temporales no estaban en posición de protestar. Sin embargo, ya a finales de la década de 1960 comenzaba a sentirse cierta capacidad de organización entre estos obreros, hecho que preo- 
cupó, lógicamente, a los dueños de los ingenios.

A lo largo de esa década, la agroindustria azucarera comenzó una nueva etapa en su expansión, con cambios en su estructura productiva, afectando la dinámica económica regional. Obligada a mantener su competitividad en el mercado internacional, comenzó la tecnificación, al menos parcial, de los procesos de trabajo ligados a la cosecha. Esto, además, resultaba conveniente para disminuir la presencia masiva de trabajadores en el ingenio, con lo que se limitaba su capacidad de resistencia organizada, que por entonces estaba aumentando en las provincias del noroeste argentino (Gordillo 1995). La mecanización de la carga y el transporte se extendió rápidamente a todos los ingenios, pero la del corte de la caña fue más lenta. Aunque la demanda global de mano de obra cayó drásticamente, los factores recién mencionados, sumados al bajo costo del cosechero manual, hicieron que persistiera una relativamente importante demanda de mano de obra estacional para la cosecha de la caña (Rutledge 1987; Gordillo 1995).

Cada campaña terminaba alrededor del 15 de noviembre. El calor y las moscas hacían insoportable el trabajo, y los casos de disentería y deshidratación entre los niños aumentaban. Era tiempo de regresar al terruño. Santiago describe la impaciencia con la que esperaba la paga, que se demoraba entre una semana y diez días. Eran días de preparativos para el regreso, despedidas de los vecinos y amigos del lote, en los cuales se festejaba, pero básicamente, días de espera y aburrimiento en los que no había mucho en qué ocuparse. Eran frecuentes los conflictos con respecto a lo que les correspondía de paga pero, generalmente, se aceptaba la palabra del capataz por miedo a no ser vuelto a contratar en la siguiente cosecha. Los más desprotegidos en este aspecto eran los trabajadores de origen boliviano que, en su gran mayoría, eran indocumentados $y$, por ende, no podían recurrir a las autoridades ni a los sindicatos para reclamar por sus derechos.

Los trabajadores regresaban a sus localidades de origen en las tierras altas, o bien migraban hacia otras cosechas para subsistir hasta la próxima campaña del azúcar. Los que volvían a sus localidades debían ocuparse de las actividades agropastoriles: preparar las parcelas de cultivo y sembrar, reparar los corrales, marcar los animales, carnearlos y otras tareas que, generalmente, se reservaban a los hombres. El dinero que traían de la zafra debía administrarse bien para subsistir durante el año. La migración temporal era una estrategia que permitía a las unidades domésticas campesinas mantener y reproducir su modo de vida, aunque a un costo muy alto en cuanto al sacrificio que esto implicaba para la familia. Movilizar dos veces por año a toda o parte de la familia, que los niños dejaran la escuela, separarse de los parientes del pueblo y la hacienda, resultaba difícil. Los hombres entrevistados, al referirse a este "sacrificio", lo hacen con un sentido de orgullo. En el relato, el sacrificio se traduce en: "es trabajo de hombres" o "ahí me hice hombre", "no cualquiera aguanta”. Ser zafrero se relaciona con el prestigio: ser trabajador, ser hombre proveedor.

Los cuatro entrevistados siguieron concurriendo a la zafra hasta alcanzar la edad en que se permitía entrar en la mina El Aguilar: los 20 años. Algunos lo hicieron pasando previamente por el servicio militar. Esta decisión podría relacionarse, desde una mirada estructural, a que, como se ha visto, a fines de la década de 1960 se redujo drásticamente la demanda de mano de obra en la industria azucarera y, a la vez, la minería en la provincia estaba en pleno auge. Desde el punto de vista de la familia, la decisión de migrar a la mina se traduciría no en una necesidad de maximizar los ingresos, sino en la de minimizar los riesgos. Los parientes y vecinos que ya se encontraban viviendo en el campamento minero proveían la posibilidad de una vivienda donde hospedarse y facilitaban la integración. El trabajo minero representaba la posibilidad de un ingreso anual mensual fiscalizado, en un ambiente natural menos hostil, para ellos, que el de la zafra.

\section{La vida en la mina}

Ceferino proviene de Rinconada, también en la puna de Jujuy. El clima de Rinconada es menos apto para la agricultura que en Miyuyoc o Chaupi Rodeo, y las unidades domésticas son básicamente minifundios ganaderos. La existencia de oro de aluviones en la zona y la cercanía de dos explotaciones mineras importantes (Pirquitas y El Aguilar) resultan en un menú de estrategias algo distinto. A diferencia de los padres de los anteriores entrevistados, el de Ceferino alternaba el trabajo estacional en la zafra con la búsqueda de oro en las cercanías de Rinconada. La familia tenía un pequeño rebaño de ovejas y cultivos de autosubsistencia. Al igual que en los casos anteriores, los niños eran los encargados de cuidar el rebaño. Al mo- 
mento de que él comenzara a migrar a la zafra, seis hermanos menores quedaban en la casa durante el invierno junto con la madre. También en esta familia, la migración estacional a la cosecha de azúcar constituyó durante varios años la estrategia prioritaria para obtener un salario. Los ingresos por el oro eran generalmente pocos y ocasionales, por lo que la partida anual a la zafra era inevitable, a entender de Ceferino. Concurrió al ingenio Ledesma durante cuatro campañas (1964 a 1968). Allí trabajaba a la par con su padre y sus hermanos. Tomaban el tren expreso que contrataba la empresa en el mes de mayo y regresaban a Rinconada a mediados de noviembre. Entonces, el padre se iba a buscar oro y el resto de la familia se ocupaba de las actividades del campo.

La migración temporal a la zafra constituyó, en todos los casos, una estrategia transitoria. Las alternativas posteriores de trabajo asalariado en la provincia tendieron a diversificarse a fines de 1960. Fue entonces cuando se instaló en Altos Hornos Zapla una acería con el propósito de crear en Palpalá un polo de desarrollo regional. También en esa época, Celulosa Jujuy instaló cerca de allí una planta elaboradora de papel blanco empleando bagazo de caña. En 1969 se inauguró en Caimancito, departamento de Ledesma, una explotación petrolera y gasífera. (Golovanevsky 2005), mientras aumentaba notoriamente la producción del tabaco. Incluso, la cercana mina Pirquitas representaba una opción laboral dentro de la minería. ¿Por qué los entrevistados optaron por El Aguilar y no por los otros lugares posibles? En la decisión de migración, las familias tenían en cuenta la información sobre el destino provista por los familiares y amigos que regresaban periódicamente a la comunidad de origen o que enviaban remesas. La experiencia personal también era fundamental a la hora de decidir, debido a que había mayor probabilidad de migrar entre aquellos que ya habían experimentado un primer movimiento, como era el caso de los cuatro entrevistados. Otro factor de peso a la hora de decidir era la tradición migratoria previa del lugar. Las migraciones se caracterizan por la continuidad y la difusión. En los relatos se evidencia el importante papel que cumplían las redes migratorias en la decisión de hacia dónde migrar. En los cuatro casos existía ya, en El Aguilar, una extensa red de parientes y vecinos que fueron responsables del "efecto llamada". Las conexiones de la red constituyeron una forma útil de capital social que las personas utilizaron para acceder al empleo, mitigando los costes y los riesgos de la movilidad. Luego, la familia jugó un rol fundamental en la integración social y laboral de los migrantes (Massey et al. 1998). En los casos entrevistados, había entre dos y cinco parientes y diez o más paisanos que ya se encontraban en El Aguilar.

El sistema de contratación en la mina a finales de la década de 1960 difería totalmente del empleado por la zafra. No existía el sistema de los contratistas, y los hombres se presentaban directamente en las oficinas de la empresa a buscar trabajo. En el caso de Ceferino, la explotación se encontraba a $35 \mathrm{~km}$ de su pueblo, por lo que el desplazamiento no resultaba tan difícil. Además, el clima no difería demasiado y prácticamente no fue necesaria la adaptación física, como ocurría con la zafra.

Ceferino esperó a tener trabajo asalariado anual y vivienda dentro del campamento de la mina para formar su propia familia. Su pareja es oriunda del mismo pueblo que él y su noviazgo se remonta a antes de que él migrara a El Aguilar. Esta estrategia matrimonial se repite en los cuatro casos. Sin excepción, conocieron a sus futuras esposas en sus localidades de origen pero solo se casaron después de tener asegurado el trabajo asalariado, estable, en la mina. Esto representa un quiebre con respecto a la estrategia que adoptó la generación de sus padres, quienes se casaron en el pueblo de origen y adoptaron como estrategia la migración estacional a la zafra, complementada con las actividades agropastoriles. La familia permanecía en la localidad de origen conservando la relación con la tierra que siguió siendo el eje de su reproducción social. Este patrón de movilidad se mantuvo a largo plazo. Durante sus primeros años en la mina, Ceferino, al igual que los otros, era soltero. Anteriormente, según los relatos, la empresa solo contrataba solteros. Después del primer gobierno de Juan Perón comenzaron a permitir el ingreso de mujeres al campamento. Si bien, oficialmente, la política de contratar solo hombres solteros se había abandonado totalmente para finales de la década de 1960, el hecho de que los cuatro entrevistados hayan entrado solteros a la mina habla, por lo menos, de una tendencia en ese sentido. En general, el acceso a la "pieza" se demoraba, por lo que resultaba indispensable contar con parientes o conocidos que compartieran las propias.

Los hombres solteros que trabajaban en el interior de la mina se hospedaban en la corrida de solteros en el cam- 
pamento La Veta, o campamento Mina, que se ubicaba a $4500 \mathrm{msnm}$, por lo que el frío es intenso todo el año. Allí se realizaban las operaciones de extracción del mineral. Las "corridas" eran una serie de construcciones rectangulares y largas, dispuestas en hileras o alrededor de un patio central, y separadas por calles de tierra. Estaban destinadas a diferentes usos: policía, herrería, carpintería, vivienda de solteros. Muchas de estas construcciones fueron posteriormente demolidas al tomar mayor importancia el campamento El Molino. Al casarse, la empresa le otorgó a Ceferino una casa en El Molino, ubicado a $4000 \mathrm{msnm}$. Allí se localizan las instalaciones industriales destinadas a beneficiar el mineral y los núcleos que organizan la vida cotidiana: el hospital, la municipalidad, el centro vecinal, el Registro Civil, el correo, el estadio, el mercado, los dos clubes deportivos, las escuelas, los almacenes, la iglesia y las viviendas. En 1989, existían unas 1542 viviendas.

El análisis de la distribución de las construcciones del campamento da cuenta de una clara segregación territorial, según la jerarquía. En un sector separado, y resguardado por alambrado, están las viviendas para los ingenieros y el personal jerárquico de la empresa. Allí, las casas están separadas entre sí (unos treinta o cuarenta metros, aproximadamente). La arquitectura es de estilo chalet, con techo a dos aguas y cuentan con pequeños canteros, hecho que resalta por tratarse de una región árida. Estaba prohibido el acceso a esta sección a toda persona que no trabajase en el servicio doméstico o tuviera un permiso especial para hacer algún trabajo de reparación. Los "capos", en su totalidad ingenieros u otros profesionales, constituyen en todos los relatos un "otro" que, debido a su nivel de educación formal, tenía acceso a una serie de beneficios inalcanzables para los mineros. La investigación refleja cómo comenzó progresivamente a incorporarse la idea de la educación formal como factor para el ascenso social. Fue surgiendo una identificación de clase, un "nosotros", mineros. El hecho de convivir grandes grupos de trabajadores internamente homogéneos en los campamentos contribuyó a esta identificación.

Las casas de los mineros siempre fueron más pequeñas que las del personal jerárquico, aunque, de todas formas, éstas eran confortables. Al igual que en La Veta, están dispuestas en largas hileras, una pegada a la otra.
Las paredes son de ladrillos y cemento, y los techos de chapa. Todas cuentan con estufa a leña, agua corriente, un baño interior, cloacas y recolección de residuos. Estas características de confort, en comparación a las viviendas del campo, son consideradas por los cuatro entrevistados como un signo de gran progreso. En cada casa se acomoda una familia. La cantidad de habitaciones varía: hay corridas de solteros, corridas para parejas sin hijos y corridas para parejas con hijos. Los hijos podían dormir separados de los padres, a diferencia de las viviendas de los lugares de origen, donde todos dormían en un mismo cuarto, o bien, se distribuían entre dos. Las casas están diseñadas según una lógica obrera, para albergar al trabajador y su familia nuclear; no a la familia extensa como en el medio rural. Hacia 1980, punto medio de la estadía de los entrevistados en la mina - que duró aproximadamente desde 1970 a 1990 - la familia estaba compuesta por el jefe, su cónyuge y sus hijos (entre cinco y once) y, en dos casos, uno o dos nietos. En la localidad de origen quedaba la parte extendida de la familia, cuidando de los mayores, del ganado y los cultivos.

Aquí se produce un quiebre con la idea común de asociar a las familias de las comunidades campesinas del área andina, con unidades en las que coinciden la producción, el consumo, la residencia y la transmisión del patrimonio. Con el cambio de lugar de residencia de una fracción de la familia, se producen las consecuentes modificaciones en las estrategias de vida del conjunto de los integrantes. Este cambio de residencia no necesariamente implica que la familia no pueda seguir funcionando con una lógica de integridad que incluya el parentesco y que mantenga sus mecanismos de integración y control. Lo que sucedería, entonces, sería una ampliación del plano espacial donde tiene lugar la estrategia de vida. La diversificación de tareas, incluyendo las tareas no relacionadas con la actividad agropastoril, permite a la familia reducir los riesgos, tanto de los que permanecen en el campo como de los que han migrado a un medio urbano, o, como en este caso, a un enclave minero. Para ellos son importantes tanto las remesas que envían los migrantes, como los bienes que se producen en el campo (charqui, papa, etc.), que aseguran el alimento a lo largo del año a todos los integrantes de la familia.

La poca distancia entre el pueblo de Ceferino y El Aguilar les permitía regresar con cierta regularidad a su casa de 
origen y participar de gran parte de las actividades que allí se llevaban a cabo. Si bien ya no se ocupaba del campo como antes, estaba presente en la siembra, que es cuando más se precisa mano de obra adicional. Las carreteras y los caminos reducían el aislamiento de la zona donde está emplazada la explotación minera, pero la empresa mantuvo el control de los contactos con el mundo exterior. Para poder entrar o salir se requería de un permiso. Había colectivos de la empresa que transportaban al personal hasta la cercana localidad de Tres Cruces y, desde allí, hasta Humahuaca o San Salvador de Jujuy (al sur) o Abra Pampa y La Quiaca (al norte), desde donde emprendían el resto del viaje en otros medios. En los otros tres casos la distancia era mayor, pudiendo regresar solo los fines de semana o en las licencias largas. El medio de transporte, entonces, eran burros y mulas para transportar a los niños y los enseres que llevaban. Ahora, el viaje ya no tenía que ver con los ciclos agrícolas, como cuando estaban insertos en el mercado de trabajo del azúcar. Se regresaba al pueblo de origen para las vacaciones, para las fiestas o para sembrar.

Todos los hijos de Ceferino y los demás entrevistados concurrieron a la escuela primaria en El Aguilar, y muchos ingresaron luego en el secundario con orientación técnica en minería. Funcionaba, también, una escuela primaria nocturna para adultos, en la que Cecilio y Mariano completaron la formación primaria. A esto se sumaban cursos de capacitación en máquinas, electricidad, mecánica y demás habilidades necesarias en la mina. Los relatos cuentan que la empresa fomentaba el estudio como posibilidad de ascender en los puestos de trabajo. Las esposas también podían concurrir a la escuela, por lo que la educación formal comenzó a formar una parte importante en la vida cotidiana de estas familias.

Los turnos de trabajo minero eran de ocho horas, pero se permitía trabajar horas extras. Eran muchos los que trabajaban el descanso de los domingos, porque se pagaba el $100 \%$. El ingreso por horas extras significaba conseguir una buena ampliación del sueldo. La organización del tiempo libre estaba pautada: los fines de semana se realizaban campeonatos de fútbol y se proyectaban películas. Estaba prohibida la ingesta de alcohol y "andar machadito [borracho] por ahí" podía significar, por lo menos, una suspensión. El rito a la pachamama se celebraba todos los primeros de agosto en la mina. Ese día, la empresa organizaba la celebración y era el único en que se permitía tomar alcohol.

A partir de 1972, mientras que los cuatro entrevistados trabajaron allí, El Aguilar desarrolló un plan de expansión que permitió aumentar notablemente la explotación (se llegaron a producir entre 2000 y 2200 toneladas de mineral por día). Los niveles estaban separados a 40 metros uno del otro. El mineral, que se trituraba primero en la trituradora primaria, era sacado en cable carril por el nivel 8 , lo cual significaba que había que transportarlo hacia arriba desde los niveles inferiores, de arranque, por los piques. Una vez afuera, debía ser transportado hacia abajo hasta la planta concentradora. En 1982 se abrió un nuevo túnel de 3500 metros de longitud en el nivel 18 de la mina, que conectaba directamente con la planta. Es entonces que el campamento El Molino cobró mayor importancia, por encontrarse justamente a ese nivel, y la mayor parte de personal pasó a residir allí. En la puerta del túnel se instaló un tren eléctrico de 12 carros que, de una sola vez, podía transportar 120 toneladas de material. A la vez, se comenzó con la apertura para el ingreso de camiones por rampas a niveles inferiores al 18 . El nivel 1 se encontraba a 4800 metros sobre el nivel del mar, y el nivel 18, a 4040. La extensión del laboreo en el sentido norte-sur era de alrededor de 2200 metros. Si se sumaban las distancias recorridas por las galerías, se llegaba a más de $100 \mathrm{~km}$ (Lavandaio 2004).

Las referencias a las dificultades que presentaba el trabajo, los accidentes y demás sinsabores que sucedían en la explotación, no surgen en las primeras entrevistas, sino bien entrada la segunda o tercera visita $y$, aun entonces, solo a instancias de preguntar explícitamente por el tema. Cuando ya habían quedado totalmente claros todos los beneficios que "provéa" la empresa El Aguilar, se pudo conversar sobre estos aspectos negativos del trabajo. Es evidente la existencia de una deuda moral implícita con la empresa proveniente de estos "dones" que generaban fuertes lazos de reciprocidad por parte de los empleados. Estos lazos, sin embargo, no impidieron que se desarrollara una importante actividad sindical. Durante la permanencia de los cuatro entrevistados en la mina El Aguilar hubo varias huelgas y movimientos de protesta. Se destacó un conflicto que los medios llamaron "El Aguilarazo". Aun hoy, este episodio y el líder sindical de Avelino Bazán, secuestrado y desaparecido en 1978 por 
la dictadura militar, ocupan un importante lugar en la memoria colectiva, no solo de los mineros, sino de los jujeños en general. Es importante recordar el contexto en el cual se desarrollaba esta actividad. A finales de la década de 1960, y durante los primeros años de la década siguiente, Argentina conoció gran cantidad de conflictos laborales en las fábricas de todo el país. La explotación minera El Aguilar no fue ajena al clima general de huelga y movilización de los obreros. Sin embargo, ya en 1944 y 1964 los obreros habían logrado reivindicaciones tales como aumentos salariales, la creación del sindicato, el aumento del seguro de vida y la indemnización por despido. Cuando Ceferino y los demás entrevistados comenzaron a participar en el movimiento de defensa de sus derechos laborales, ya existía una fuerte experiencia de lucha en ese sentido.

Las redes migratorias tuvieron un importante rol en la llegada y posterior adaptación de los campesinos a El Aguilar. El trabajo asalariado en la explotación minera puede entenderse como parte de una estrategia de diversificación de ingresos, en la cual se complementa lo producido en la localidad de origen con el salario y las mercancías que proveían los migrantes. La estrategia de diversificación da seguridad a la unidad doméstica, y es posible en tanto la misma sigue funcionando como unidad, aunque en un espacio más extenso. Las remesas y la participación de los migrantes en la vida de la localidad de origen continuaron a través de su permanencia en la mina. La educación formal, como estrategia de ascenso social, cobró una importancia cada vez mayor. Por otra parte, lentamente comenzó a solidificarse la identidad minera, que será importante en el momento de insertarse en Tilcara, tras ser despedidos de El Aguilar. Esta cuestión será analizada en el relato de Mariano.

\section{Desempleo y nueva emigración: la llegada a Tilcara}

Mariano nació y se crió en Portillo, un pequeño paraje que se encuentra a unos $20 \mathrm{~km}$ de El Aguilar. La oferta de recursos de la zona es muy similar a la existente en Rinconada. La diferencia más importante radica en que Portillo no se encuentra muy cerca de los ríos donde se busca oro. En cambio, está más próximo a las salinas. En esta zona existía la costumbre de emprender largos viajes con tropas de burros con la finalidad de trocar sal, lana y carne por maíz y papa, que se cultivaban en las quebradas y valles templados (Cipolletti 1984). Estas transacciones se llevaban a cabo en las ferias regionales o a través del intercambio entre "colegas de trueque" (Karasik 1985). Otra diferencia entre Mariano y los demás entrevistados es que, si bien él concurrió a la zafra como ellos, comenzó a hacerlo cuando era más grande, a los 18 años, y participó en solo dos campañas en el ingenio Ledesma. Consultado acerca de por qué esperó hasta los 18 para ir a la zafra, expresa que en su familia eran solo dos hijos varones, y mientras el hermano mayor se iba a la zafra desde más chico, él quedaba a cargo del resto de la familia. Luego migró hacia El Aguilar, donde comenzó trabajando de albañil en la construcción y, más adelante, se incorporó al trabajo propiamente minero. Mariano terminó su escuela primaria en El Aguilar. Allí vivió por casi veinte años, hasta que lo despidieron.

A fines de la década de 1980 comenzó un largo período de crisis para la minería. Los minerales explotados por El Aguilar sufrieron una importante baja en los mercados internacionales y, sumado a esto, los gravámenes impuestos desde el gobierno nacional dificultaban la capacidad de exportación. El Aguilar era, en ese entonces, el mayor productor de plomo, plata y zinc del país, y había adquirido nuevas y modernas maquinarias que hacían más eficiente la extracción del mineral (Salizzi 2014). En ese momento se inició, para los trabajadores, una etapa de ansiedad e incertidumbre. Comenzaron a circular rumores acerca de los despidos. Algunos aceptaron el retiro voluntario propuesto por la empresa. Otros decidieron esperar que el temido despido no les tocase a ellos. Para las familias, significaba el drástico fin de un proyecto y un estilo de vida. Los hijos de los mineros, casi en su totalidad, habían nacido y se habían criado allí. La vida cotidiana de las familias giraba en torno a los horarios y los tiempos de la explotación. La sirena, los turnos de trabajo, las escuelas, las actividades recreativas, la certidumbre de cobrar el sueldo los días cinco y veinte de cada mes y las comodidades de las viviendas, entre otros aspectos, formaban parte del universo cotidiano. Los hombres que habían forjado su identidad minera y cuyo trabajo les proporcionaba, además, un fuerte sentido de dignidad, al ser despedidos se sentían desahuciados y desprotegidos. Las estrategias de reproducción que durante buena parte de sus vidas les habían permitido vivir, mantener a su familia, ir mejorando las condiciones de vida y las perspectivas para el futuro, se desmoronaron de forma repentina y terrible. 
Los cuatro entrevistados tenían, a principios de la década de 1990, alrededor de 50 años. Habían vivido al menos la mitad de sus vidas en El Aguilar. En las entrevistas esgrimen diferentes razones para explicar los despidos, y ninguno parece querer detenerse en este tramo de su historia. Mariano fue despedido de El Aguilar en 1990. Es política de la empresa que solo los empleados pueden tener acceso a la vivienda. Por eso, tuvo que dejar la casa donde habían nacido sus hijos y vivido por 23 años. En ese momento de migración forzosa, de incertidumbre y ansiedad, Mariano y su familia tuvieron que decidir su próximo destino. Él tenía hijos en edad escolar. La alternativa de regresar a Portillo significaba que sus hijos no terminaran la educación secundaria. A través de los años, la educación formal se había transformado en parte de la vida cotidiana de las familias de los mineros y era vista como factor de ascenso social y progreso. La inversión en educación puede identificarse, aquí, como una de las estrategias de reproducción a través de la cual la familia buscó mantener o mejorar su nivel de vida (Bourdieu 1993). La existencia de una escuela técnica en el pueblo de Maimará (ubicado a solo seis kilómetros al sur de Tilcara) y de dos secundarios en Tilcara (uno normal, y el otro, bachillerato para adultos) fue un factor importante en el momento de decidir hacia dónde ir. Es de notar que tanto los entrevistados, excepto Ceferino, como sus esposas, no habían terminado el primario en sus localidades de origen, pero la totalidad de sus hijos terminaron tanto el primario como el secundario. Tres de los hijos de Santiago han proseguido sus estudios en la Universidad Nacional de Córdoba.

Existía entre algunos mineros de El Aguilar la costumbre de ahorrar y comprarse un terreno o una casa en alguna localidad urbana. Cuando los hijos llegaban a la edad del secundario, las mujeres se mudaban con los hijos a estos pueblos. Éste es el caso de Cecilio, que había comprado una casa en Tilcara al poco tiempo de trabajar en la mina. También Santiago había invertido en una vivienda en Palpalá, que para ese entonces era el centro de una pujante industria del acero con los Altos Hornos Zapla como eje. Pero ni Mariano ni Ceferino, al momento de ser despedidos, contaban con terrenos o casas en otro lugar que no fuese su localidad de origen. Las opciones eran múltiples. Como se señaló en acápites anteriores, los lazos entre ellos y su pueblo de origen y el control sobre sus parcelas y sus animales persistieron. La primera opción en todos los casos era regresar a la localidad de origen. Pero esto significaba privar a los hijos del acceso a la educación formal, que ya era considerada como indispensable. Las perspectivas de regresar a la vida del campo tampoco resultaban muy atractivas, especialmente si se tiene en cuenta que allí no se obtenían ingresos monetarios. Mariano se refiere al frío que hace en Portillo, a la infertilidad de las tierras y a la escasez de elementos que ya eran parte de su vida diaria. La experiencia en la mina generó otras necesidades, otro habitus, que impidió que regresara a la vida campesina en su lugar de origen. Con el tiempo, Cecilio logró conciliar ambas identidades: la campesina y la de trabajador urbano, sin perder ninguna de las dos.

Ceferino optó por regresar primero a Rinconada y retomar las estrategias que su unidad doméstica implementara tiempo atrás. A través del Plan de Apoyo a Lavadores Artesanales, de la Dirección de Minería Provincial, se dedicó al trabajo de buscador de oro, como años antes hiciera su padre. Sin embargo, un rápido vistazo a los indicadores sociales que presenta Rinconada permitirá comprender lo difícil de esa situación, especialmente luego de haber vivido en el enclave urbano El Aguilar. Entre 1991 y 2001, la población del departamento de Rinconada decreció en un 25,3\% (INDEC). Las razones de esta reducción en la población pueden encontrarse, probablemente, en la alta tasa de desempleo, la problemática educativa y la situación sanitaria extremadamente precaria. En 2001, en Rinconada solo el 10,5\% de los jóvenes asistía a algún nivel de una institución educativa (en comparación con un $43 \%$ del total de la población urbana provincial) y el o\% accedía a una educación superior. Rinconada era, en ese entonces, uno de los dos departamentos con mayor índice de analfabetismo de la provincia. La situación social de Rinconada era la más extrema de toda la región.

Las posibilidades de reinsertarse en la industria minera de la provincia eran casi nulas. Altos Hornos Zapla se había privatizado y había reducido drásticamente el personal. Mina Pirquitas, la explotación minera más cercana, se declaró en quiebra en esa misma época (Fleitas y Kindgard 2006; Teruel 2006). Santiago, en primera instancia, migró a la ciudad de Palpalá donde se había comprado una casa en los años setenta, cuando Altos Hornos Zapla estaba en pleno auge. Pensaba que él y sus hijos varones 
podrían trabajar allí. Sin embargo, al llegar, la realidad era otra. A la privatización de los Altos Hornos se sumó la privatización de otras empresas públicas — como la de energía eléctrica-, y el cierre de las explotaciones petrolíferas y del ramal ferroviario a La Quiaca. Todo lo anterior significó la pérdida de numerosos puestos de trabajo (Golovanevsky 2005). Se congeló, a la vez, la planta de trabajadores estatales, y la economía de la provincia fue incapaz de absorber a la gran cantidad de trabajadores desempleados que se generaron entonces. Ante este panorama, Santiago y su familia se vieron en la necesidad de volver a migrar.

Los centros urbanos que se encuentran a la vera de la Ruta Nacional 9 se presentaban como otra de las alternativas para migrar. Las ciudades puneñas de La Quiaca y Abra Pampa fueron destino de muchos mineros, al igual que Humahuaca, Tilcara y Maimará. La migración hacia estos pueblos alcanzó su punto máximo en la década de 1990 . Se estima que entre 60 y 70 familias de exmineros se instalaron en Tilcara (Janoschka y Reboratti 2003). En el relato de Mariano se refleja nuevamente la importancia de las redes migratorias en la elección del destino: se refiere a los conocidos que habían migrado antes que él, y a través de los cuales supo del terreno que estaba en venta y que finalmente compró. También le informaron sobre las posibilidades laborales que existían. Mariano, en primera instancia, y luego los demás entrevistados, finalmente eligieron Tilcara como destino de migración. Esta localidad se encuentra aproximadamente en el centro geográfico de la Quebrada de Humahuaca, donde el clima es notoriamente más benigno que en las localidades de origen de los entrevistados para el cultivo de variadas frutas y hortalizas.

La principal actividad económica que se desarrollaba en Tilcara cuando llegó Mariano era la agricultura comercial de pequeña escala, dirigida a los mercados urbanos regionales de San Salvador de Jujuy, San Miguel de Tucumán y Santiago del Estero. La ubicación de la Quebrada de Humahuaca y su fácil acceso favorecieron el comercio. El cierre del ferrocarril produjo un efecto "cuello de botella" en la comercialización, al pasar los productores a depender de los intermediaros. La existencia de la horticultura intensiva, que generaba ciertos ingresos monetarios, atrajo a la población masculina de otras zonas de la provincia (Arzeno y Castro 1998). Las actividades asociadas al sector terciario, particularmente en las dependencias gubernamentales, fueron aumentando progresivamente en importancia. La Quebrada de Humahuaca presentaba, además, una ventaja comparativa con respecto a la puna. Durante la década de 1990 se afianzaron allí varias ONG con financiamiento internacional, que orientaban su trabajo al desarrollo rural y brindaban microcréditos, capacitación y asistencia técnica a los productores de la zona. A esta oferta se sumaban diferentes programas agrícolas estatales. El mejoramiento de los caminos a principios de la década de 1990 impulsó el desarrollo de la actividad turística, que ya desde principios del siglo XX atraía a las familias de las clases altas de Tucumán, Salta y Jujuy (Benedetti 2003). La industria hotelera y de servicios para el turista, aunque incipiente, comenzaba a demandar mano de obra, tanto para la construcción como para la atención de los turistas. Además, Tilcara poseía otras ventajas adicionales: tenía un hospital, dos escuelas primarias, dos escuelas secundarias - más la técnica de Maimará-, un terciario y acceso al agua potable. En suma, allí existía, en contraste con lo que sucedía en la puna, variedad de recursos y posibilidades de inserción laboral.

La composición de las cuatro unidades domésticas al momento de esta última etapa migratoria es relevante para poder comprender las estrategias implementadas por cada una. Las familias tenían entre seis y once integrantes (padres e hijos). Entonces, la relación entre productores y consumidores era más favorable, ya que la totalidad de los hijos de los matrimonios originales habían llegado a la edad económicamente activa. Ya en 1990 comienzan a sumarse los nietos a la unidad doméstica, en general, descendientes de las hijas mujeres solteras, que se crían junto a los abuelos.

El relato de Mariano da cuenta de hasta qué punto los años vividos en El Aguilar lo identifican más que cualquier otro tramo de su vida. Él no se reconoce como campesino ni zafrero, sino como minero. El hecho de no trabajar más en la explotación no quita, a ojos los propio y de los demás, esa identidad. El ser minero es ahora, y fue en el momento de llegar a Tilcara, su orgullo, lo que lo identificaba como hombre de trabajo. Representaba la dignidad de haber sabido asumir riesgos y de haber tenido responsabilidades dentro de una estructura jerárquica. A su vez, funcionó como un estigma para él y su familia, ya que la población local identificaba en forma despectiva al 
minero como "extranjero", "buscapleitos" y "bueno para nada”. Evidentemente, los mineros y sus familias, aunque muy cercanos culturalmente a los tilcareños, habían adquirido otro habitus, otras pautas de consumo, gustos en cuanto a la construcción de las viviendas, forma de vestirse, que los diferenciaban de la población local. Se habían convertido en un "otro" que bien podría haber llegado de otro país; en definitiva, que no pertenecía a ese lugar. Ante esta situación, los "mineros" o "ex-mineros" (como se los identifica hasta hoy) tendieron a aglutinarse, formando "barrios mineros".

Mariano compró dos hectáreas de tierra en las afueras de Tilcara. Durante los primeros tres años complementó la agricultura de autosubsistencia con los ahorros que le quedaban de la indemnización por despido. Sus hijos continuaron los estudios en las escuelas de Tilcara y su esposa volvió a ocuparse de las tareas del campo, complementando las realizadas por él. Los hijos prácticamente no trabajaban en el campo; solo lo hacían durante la siembra o la cosecha. Al no tener suficiente tierra en Tilcara para criar animales, Mariano mantuvo su ganado en Portillo. Al terminarse el dinero de la indemnización, buscó empleo en el pueblo y, curiosamente, volvió al trabajo con el que había ingresado a El Aguilar: la albañilería. Sus hijos no regresaron a la puna. En cambio, migraron a los grandes centros urbanos del país. Pero regresan puntualmente en agosto, para "darle de comer a la tierra", y en Semana Santa, cuando participan de la peregrinación a la virgen del Abra de Punta Corral. Mariano y su esposa regresan periódicamente a su localidad de origen para visitar a la familia, llevando maíz y frutas de su quinta y trayendo carne y charqui.

La elección de Tilcara como destino habla, entre otros aspectos, del papel de las redes migratorias en la estrategia de minimización de riesgos que adoptó la unidad doméstica de Mariano. El hecho de que Tilcara fuese un destino ya conocido entre los mineros de El Aguilar fue un factor aglutinante. Estas redes le permitieron encontrar tierra donde establecerse, algo que no resultaba tan sencillo en un lugar donde la tierra fértil es escasa y hacia donde existía un flujo migratorio importante. También permitieron a su familia sobrellevar la etapa de adaptación a una nueva vida, marcada por la no aceptación de la población local hacia los recién llegados. Además, la estrategia de inversión en educación tuvo especial importancia en esta elección. La oferta educativa de Tilcara incluía una escuela técnica en el cercano poblado de Maimará. Mariano esperaba que sus hijos varones egresaran de allí con un oficio. La escuela normal de Tilcara fue vista como lugar para que las hijas mujeres se recibieran de maestras y tuvieran también un oficio.

Dentro de Tilcara, la elección de un sector rural y la inversión de parte del dinero de la indemnización en la adquisición de tierras para cultivar, reflejan que la unidad doméstica conserva como capital social, parte las estrategias propias del habitus campesino. La casa de Mariano en Tilcara tiene idéntica estructura que la de su comunidad de origen: piezas rectangulares que se fueron agregando, con el correr de los años, en torno a un patio central donde se encuentra la mesa y donde se lleva a cabo la mayor parte de las actividades cotidianas, además del horno de barro, el espacio para secar la cosecha de maíz y de frutas, $y$ los alambres para preparar el charqui. No hay agua corriente, y la casa cuenta con una letrina a cielo abierto. El riego es realizado por una acequia y canales (Mariano remarca el hecho de que allí nunca falta el agua). En su terreno se siembra lo suficiente para una economía de autosubsistencia, que se complementa con la carne proveniente de la Puna. El dinero sobrante de la indemnización se utilizó como ingreso extrapredial: recién cuando éste se acabó, Mariano retomó el trabajo fuera del predio. La amplitud del plano espacial de la unidad doméstica se mantuvo por más de una década. Sin embargo, con el correr de los años el nexo con la comunidad de origen se fue espaciando $y$, al momento de la entrevista, las visitas a Portillo eran solo para las fiestas. El ganado es casi inexistente, ya que allí no quedan jóvenes de la familia que se ocupen de él. Nuevamente, la diversificación de tareas habla de una estrategia de minimización de riesgos. Los hijos de Mariano, nacidos y criados en El Aguilar, no tienen el habitus de sus padres. Su experiencia cotidiana ha sido prácticamente urbana durante toda su vida. Ellos, al terminar los estudios secundarios en Tilcara, han migrado a centros urbanos más grandes, como San Salvador de Jujuy y Buenos Aires. El abandono de la condición campesina de esta generación de la familia es completo.

Ceferino y su familia habían migrado a Rinconada luego del despido, donde vivieron casi dos años. Durante la estadía allí, la familia se instaló en el casco urbano del pueblo para que las hijas menores terminaran la escue- 
la primaria. Los hijos varones comenzaron a ocuparse del ganado que tenían él y sus padres, ya mayores, y a mejorar las tierras de cultivo. Ceferino se incorporó a un programa del gobierno, a través del cual se organizaban grupos para buscar oro. La dinámica cotidiana cambió con respecto a la que llevaban en El Aguilar. Ahora, la esposa de Ceferino debía salir todos los días a buscar leña y ocuparse de los animales, además de las tareas de la casa. Ya no trabajaba fuera del hogar como en El Aguilar. Si bien algunos de los hijos tenían edad para incorporarse a algún trabajo extrapredial, no pudieron conseguirlo. El único ingreso monetario con el que contaban era el que provenía de la búsqueda de oro, que era ocasional y magro. La indemnización se utilizó en primera instancia para la compra de una casa en el pueblo, y luego para adquirir mercadería y ropa. La familia fue racionando este dinero. Los años en Rinconada surgen en el relato como sumamente penosos y de pocas esperanzas. Luego, un golpe de suerte cambió las perspectivas para esta familia. Ceferino encontró una pepita de oro de medio kilo. La familia decidió invertir ese dinero, junto con lo que quedaba de la indemnización, en la compra de un terreno de aproximadamente seis hectáreas en Tilcara. Ceferino explica la elección de Tilcara como destino, en primer lugar, por la educación de sus hijos; en segundo lugar, por la fertilidad de su tierra. En los años anteriores, varios conocidos de la familia, también ex-mineros, habían migrado hacia Tilcara y traían noticias a Rinconada. Fue, al igual que en el caso de Mariano, a través de esta red de conocidos, que Ceferino consiguió el terreno que actualmente ocupa. Esta familia también sufrió el rechazo por parte de la población local al llegar y, si bien habían adquirido sus tierras, se los acusó de haberlas usurpado. Al poco tiempo de llegar consiguió, a través de un pariente, un trabajo estable en la municipalidad de Rinconada. Allí trabaja de corrido dos semanas, viviendo en la casa donde se crió y en donde tiene sus animales y algunos cultivos. Al término de las dos semanas se desplaza hasta Tilcara, donde permanece durante el fin de semana y tal vez unos días más. Ceferino está en constate movimiento entre Rinconada y Tilcara, donde se desarrolla la vida cotidiana de la familia. Nuevamente, la estrategia de ampliar la escala espacial en la que se desarrolla la unidad doméstica está presente en esta familia. En la Puna, mantiene un pequeño rebaño de ovejas para autoabastecerse de carne. A esto se suman los cultivos de habas, arvejas y papas. También allí está el puesto de trabajo de Ceferino, que provee tanto dinero como seguro médico para la familia. En Tilcara, cuatro de sus hijos varones se ocupan tiempo completo de trabajar el campo. Sin embargo, ninguno de los hijos se desplaza a Rinconada a trabajar el campo allí: no lo sienten como lugar de pertenencia.

Santiago había migrado desde la mina hacia Palpalá. Al poco tiempo, la situación social y el clima de esta ciudad lo decidieron a migrar nuevamente. Desde que salió de El Aguilar supo que no quería volver a vivir en el campo ni realizar tareas rurales. Al tener que volver a migrar, la familia buscó un lugar urbano donde insertarse laboralmente. Tilcara, con un sector turístico incipiente, ofrecía esa oportunidad, a su entender. Las redes migratorias - el hermano de Santiago había migrado a Tilcara tiempo antes - también fueron factor de atracción hacia este destino. Su casa se encuentra en el casco histórico del pueblo, a veinte metros de la plaza principal. Cuenta con agua potable y todas las comodidades propias de una vivienda urbana. Para comprar la casa, Santiago vendió la camioneta que había adquirido durante su estadía en la mina, pero decidió conservar la vivienda de Palpalá en caso que sus hijos la necesitasen mientras estudiaban o trabajaban. También menciona la preocupación por el estudio de los hijos: la existencia de la escuela técnica de Maimará surge como razón de peso a la hora de elegir el destino. Al poco tiempo de llegar, y ya instalados en su nueva casa, comenzó a vender productos textiles traídos de Bolivia en un puesto de la feria que funciona en la plaza principal de Tilcara, atendido por él y su mujer. Los ingresos de la familia se compusieron por muchos años de las ganancias de este puesto y de su jubilación. Todos sus hijos e hijas asistieron a la escuela secundaria y tres de ellos a la universidad. Una de las hijas regresó de la universidad, se casó y convive con sus padres. Han abierto un kiosco y un locutorio telefónico en la casa. Los demás hijos migraron a otros centros urbanos. Regresan ocasionalmente de visita, o Santiago los visita en sus casas. Aquí, la estrategia de la familia es claramente diferente a las de los otros tres. Sin embargo, Santiago continúa yendo periódicamente a su localidad de origen en donde cultiva habas y arvejas en una pequeña parcela. La cantidad que siembra no alcanza para hablar de autosubsistencia. La familia no tiene animales, ni hay quien resida permanentemente en Chaupi Rodeo, así que los viajes de Santiago ocurren en primavera y verano, época de siembra y cosecha. Los hijos no regresan al campo. 
Al salir de El Aguilar, la familia de Cecilio migró directamente a Tilcara. A los pocos años de haber comenzado a trabajar en El Aguilar, él y su esposa habían comprado un terreno en esa localidad que, si bien hoy se encuentra en el casco urbano, en ese momento estaba ubicado el borde periurbano de cultivo de alfalfa. A diferencia de Mariano y Ceferino, Cecilio solo compró un pequeño terreno con espacio suficiente para la casa. Allí se instaló la familia, y los hijos continuaron sus estudios en las escuelas locales. Al poco tiempo falleció su suegra y, entonces, él y su mujer migraron a Miyuyoc para encargarse del ganado. Vivieron en el campo durante un año, pero no pudieron readaptarse. Fue entonces que decidieron regresar a Tilcara. Cecilio narra con gran pesar el hecho de haber tenido que deshacerse del ganado, al que considera como parte de la familia. Una vez en Tilcara, comenzó la búsqueda de trabajo. Los conocimientos adquiridos en el manejo de máquinas le permitieron conseguir un trabajo en la municipalidad local. Si bien no había sido dirigente sindical, participó en las huelgas y movimientos de protesta en la mina. Los años como sereno del sector del staff de El Molino lo habituaron a tratar con personas en posiciones jerárquicas superiores. El sentido de orgullo y dignidad como trabajador capacitado surgen en el relato al contar una anécdota sobre cómo se posicionó en su trabajo en la municipalidad frente a abusos o malos tratos por parte del intendente local. Al dejar el trabajo en la municipalidad, consiguió un subsidio del Estado y durante dos años trabajó como jardinero en forma ocasional. La esposa comenzó a vender empanadas para complementar los ingresos, pero encontró dificultades para hacerlo, ya que era identificada como "esposa de minero" y, por tanto, "de afuera". Al tiempo, Cecilio se empleó como peón de campo en una finca cercana a su casa. Allí, como parte de su sueldo, tenía un cuarto de hectárea de tierra donde sembraba el maíz para las humitas de su esposa y una chacra para el autoabastecimiento familiar. Además, tenía un corral con un pequeño rebaño de ovejas. Durante la semana se instalaba en una pequeña casa en el campo y combinaba su trabajo con el cuidado de su chacra y su rebaño. Los fines de semana, su esposa lo acompañaba en el campo, y luego regresaban a la casa en el pueblo, a solo un kilómetro. Esta combinación de salario e ingresos no monetarios le permitía combinar el habitus rural con el urbano. Los hijos de Cecilio no se ocuparon de actividades relacionadas con el campo. Solo cuatro de ellos permanecieron en Tilcara. Los demás migraron, apenas terminaron el secundario, a varios puntos de la Patagonia. Allí trabajan en fábricas y emprendimientos privados. Los cuatro hijos que permanecen en Tilcara se casaron y dejaron la casa paterna. Los varones trabajan como remiseros y las mujeres son empleadas en un hotel y en un restaurante. En este caso, el auge del turismo fue abriendo oportunidades laborales a los jóvenes, y muchos optaron por quedarse allí.

\section{CONCLUSIONES}

Los hombres cuyas trayectorias de movilidad se han analizado en este trabajo pertenecen a la generación que nació a mediados del siglo XX en pequeños poblados de la puna jujeña. Todos formaban parte de unidades campesinas en las que la estrategia de migración temporal hacia la zafra azucarera de las tierras bajas estaba instalada desde la década de 1930. Sus madres no accedieron a la educación formal y fueron analfabetas. Las mujeres de su misma generación comenzaron a asistir a la escuela pero, generalmente, no completaron sus estudios. La inversión en educación no era parte del repertorio de estrategias de reproducción social de esas familias. Los padres migraban anualmente a trabajar en la cosecha de la caña, y ellos se sumaron a esta movilidad cuando alcanzaron la adolescencia. Esta práctica permitía a las familias complementar los ingresos por las actividades prediales de subsistencia.

Incorporarse a esta dinámica implicó para estos hombres salir por primera vez de sus comunidades de origen y cambiar una movilidad local hacia los puestos de pastoreo o, excepcionalmente, centros urbanos próximos (como Humahuaca), por desplazamientos a grandes distancias (a Ledesma, por caso). El trabajo en la zafra significó un primer momento de incorporación de hábitos formales de trabajo - horarios, eficiencia, etc. - que conformaron un capital que aprovecharían una vez establecidos en el enclave minero. Si bien estos hombres se incorporaron a la dinámica de migración temporal a la zafra, lo hicieron con perspectivas diferentes a las de sus padres. Para estos últimos, esa movilidad formaba parte de una estrategia permanente que mantuvieron hasta que la reducción de la demanda de mano de obra para la industria azucarera, o su propia edad, pusieron fin a la posibilidad de trabajar allí. En cambio, sus hijos - los sujetos de esta investigación - asumieron esta movilidad como una estrategia 
temporal hasta que pudieran emplearse en la mina El Aguilar. Esto significó un corte con el ciclo que habían tenido sus antecesores. A su vez, implicó cambios en la estrategia matrimonial. Los cuatro sujetos, a diferencia de sus padres, decidieron no casarse mientras migraran a la zafra, por razones diferentes: uno, consideraban que el clima de las tierras bajas era insalubre para los hijos; dos, las condiciones de trabajo, de vivienda y de salud eran inadecuadas; y tres, sabían que tendrían más posibilidades de ser contratados en El Aguilar mientras fueran solteros. La experiencia en la cosecha del azúcar generó un habitus que facilitó su inserción en el mercado de trabajo minero.

Los cuatro sujetos tenían parientes o vecinos que habían migrado con anterioridad hacia El Aguilar. A través de ellos, comenzaron a enterarse de los saberes y las prácticas propias del trabajo minero. Al alcanzar aproximadamente los 20 años de edad, también ellos migraron a este lugar. Allí, por primera vez en sus vidas, se introdujeron en una estructura con una lógica capitalista. En el establecimiento y la adaptación a este medio, radicalmente diferente al propio, tuvo suma importancia la existencia de las redes migratorias. Las redes sociales fueron importantes tanto en la información previa sobre la vida en la mina, que generó el "efecto llamada", como en facilitar el ingreso, sirviendo como referencia de los recién llegados y, por último, alojándolos hasta que consiguieron sus viviendas propias. Estas redes prueban que la migración y la industrialización no llevaron indefectiblemente a la ruptura de la familia y los vínculos familiares. Al contrario, como se ha visto, las relaciones de parentesco fueron importantes en la migración y en la adaptación a la vida industrial.

Los cuatro entrevistados se casaron en los primeros años de su estadía en la mina El Aguilar con mujeres que habían conocido en sus lugares de origen. Así, accedieron a una vivienda familiar en las corridas de los campamentos de la mina. La experiencia adquirida durante la estadía en la mina produjo profundos cambios en la vida cotidiana y el habitus de estas personas. En principio, los horarios y los turnos de trabajo fijos establecieron una rutina estricta para la familia. Los hombres prácticamente estaban ausentes del hogar, ya que buscaban trabajar horas extras para mejorar sus salarios. El tiempo libre incorporó cuestiones rutinarias: partidos de fútbol y cine los domingos, deportes durante la semana. Las mujeres y los niños no tenían que ocuparse de los animales ni de buscar leña o agua; la empresa se ocupaba de ello. El acceso a la medicina, que antes resultaba prácticamente imposible, comenzó a formar parte de la cotidianeidad.

La participación activa en el gremio de los trabajadores mineros y en las protestas y movilizaciones de los trabajadores, resultó también en la incorporación de prácticas tendientes a defender sus derechos (saber que los tenían, en primera instancia) y a identificarse como trabajadores dentro de un orden jerárquico. Aprendieron a gestionar frente a la autoridad, incorporando para ello tanto los medios escritos, las asambleas y las medidas colectivas para ejercer presión. Hasta entonces campesinos, los sujetos de esta investigación se identificaron a partir de ese momento y en el futuro como "mineros".

El acceso a la educación formal, la posibilidad concreta de dedicarle tiempo, y su visualización como factor de ascenso social, es un capítulo aparte. Este aspecto tuvo mayor impacto sobre el futuro de estas unidades domésticas por sobre todos los demás. Los cuatro entrevistados se capacitaron en la mina en cursos técnicos. Dos de ellos terminaron la escuela primaria y sus esposas también estudiaron. Esta incorporación de la educación formal en la vida cotidiana de las familias fue determinante en el momento de decidir en qué dirección migrar, luego de los despidos de la mina. Las cuatro familias eligieron Tilcara principalmente por su oferta educativa. La totalidad de sus hijos, sin distinción de género, terminaron no solo la escuela primaria sino también la secundaria, y varios de ellos continuaron estudios superiores.

A los largo de las tres generaciones identificadas, se verificó una ampliación del espectro de posibilidades y recursos a partir de los cuales diseñar sus estrategias de reproducción social. Asimismo, entre generaciones se fue ampliando el área para las movilidades vinculadas a esas estrategias. Aumentaron progresivamente las distancias y cambiaron las direcciones. En la Figura 5 se presenta, en violeta, el patrón de movilidad de la generación de los padres de los sujetos: su movilidad ocasional era a los puestos y a los centros urbanos más cercanos, seguida por la movilidad estacional por la zafra. En rojo, se puede apreciar que la movilidad de los sujetos de este trabajo se suma, en un primer momento, a la de sus padres, para luego separarse y migrar hacia la mina y a Tilcara. La 


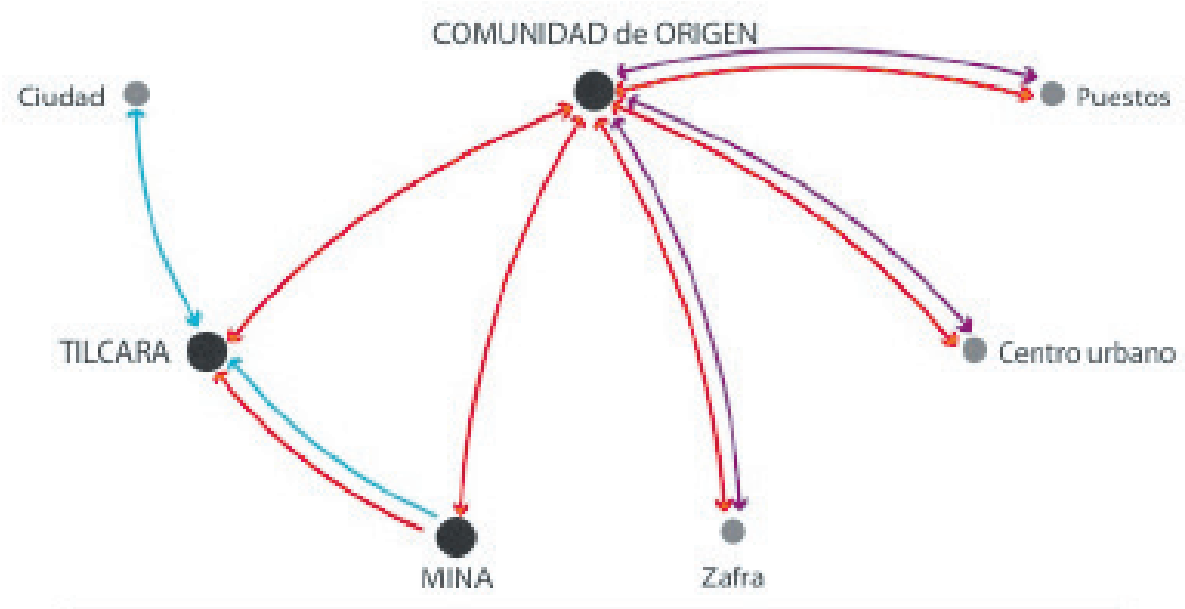

Generación de los Padres | Generación de los Sujetos | Generación de los Hijos

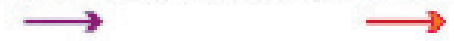

Figura 5. Esquema resumen de las movilidades.

migración de sus hijos (celeste) rompe radicalmente con la centralidad de la comunidad de origen: nacieron en la mina El Aguilar, después acompañaron a sus padres hacia Tilcara y luego permanecieron allí o emprenden otra migración, ya solos, hacia las ciudades del sur del país.

El recorrido analítico de este artículo permite llegar a dos conclusiones sobre la relación entre minería y campesinado en el contexto específico de la puna de Jujuy.

Por un lado, se puede afirmar que la minería, más que la agroindustria azucarera, contribuyó activamente al proceso de descampesinización en la puna de Jujuy, que todavía no llegó a ser total. El esquema productivo azucarero requería que la mano de obra estuviera disponible una cierta cantidad de meses, luego de los cuales se volvía prescindible. Por eso, la permanencia del esquema de pequeña producción agropastoril en sus lugares de origen, sostenida por las mujeres y otros integrantes del grupo doméstico, se volvió funcional al desarrollo agroindustrial. El trabajo en la zafra dotó a estas personas de hábitos diferentes a los que tenían en sus lugares de origen, como la organización sindical para reclamar derechos laborales. No obstante, no exigía el total desarraigo y la pérdida completa de sus prácticas tradicionales. La minería, en cambio, exigió una mayor ruptura con el mundo agropastoril, toda vez que los mineros se instalaban en la mina de manera permanente. Asimismo, promovía la acumulación de capital cultural a través de nuevas prácticas, como ordenar los momentos de ocio, cumplir ciertas rutinas cotidianas o formarse en oficios no rurales, tales como la herrería o la tornería. Una vez que la población minera fue despedida, no retomó -o lo hizo de manera marginal- sus prácticas agrícolas o pastoriles previas. La experiencia en la mina generó otras necesidades, otro habitus, que impidió el regreso a la vida campesina en su lugar de origen. A largo plazo, a lo largo de tres generaciones, esto derivó en una migración definitiva en dirección a los grandes centros urbanos, fuera de la región.

Por otro lado, en cuanto al espacio, la minería constituyó una actividad de enclave. Se insertó en el espacio rural en lugares puntuales, generando allí aglomeraciones cuyo devenir estuvo estrechamente ligado a la actividad. El pueblo El Aguilar se formó, pobló y despobló al ritmo de los auges, crisis y recomposiciones de la productividad minera. En ese pueblo no se desarrollaron otras actividades sino las que se relacionan con la extracción y exportación, fuera de la puna de Jujuy, de materia prima de origen mineral. De todas maneras, produjo ciertos reordenamientos regionales, especialmente en el sistema de caminos, ya que contribuyó a reforzar al ferrocarril como vía de extracción de productos de la región, luego reemplazado por los camiones a través de las carreteras. Aun así, no se observa un "efecto derrame" del desarrollo en la región, que mantiene su condición predominantemente agropastoril, incluso en la actualidad. 


\section{* Referencias citadas}

ARZENO, M. y H. CASTRO. 1998. Caracterización socio-ambiental de la Quebrada de Humahuaca. Suplemento Geografía Econó$\operatorname{mica} 1(3): 1-6$

BENEDETTI, A. 2001. Mujeres y producción textil en El Moreno: algunas consideraciones sobre la energización rural en la Puna jujeña. Estudios Sociales del NOA 4(3): 75-117.

2003. Los efectos de la inclusión. Transformaciones territoriales y reorganización de la red de lugares poblados en Jujuy, República Argentina, durante el siglo XX. Histoire des Alpes 8: 99-121.

2005. Incorporación de nuevas tierras durante el período de conformación del agro moderno en la Argentina: El Territorio de los Andes, primeras décadas del siglo XX. Mundo Agrario 6(11): $1-44$.

2006. Los secretos de la montaña. Minería y geografía histórica del Territorio de los Andes (1900-1943). Estudios Sociales del NOA 9(9): 5-48.

2015. El encuentro entre marca, camino y lugar. Hodografía del espacio fronterizo argentino-boliviano en la conurbación binacional de La Quiaca-Villazón. En Líneas, límites y colindancias. Miradas a las fronteras desde América Latina, A. Hernández y A. E. Campos Delgado (Comps.), pp. 27-6o. El Colegio de la Frontera Norte/CIESAS, Tijuana.

BISIO, R. F. y FORNI. 1976. Economía de enclave y satelización del mercado de trabajo rural: el caso de los trabajadores con empleo precario en un ingenio azucarero del noroeste argentino. Desarrollo Económico 61: 3-56.

BOURDIEU, P. 1993. Cosas dichas. Gedisa, Barcelona.

BRACKEBUSCH, L. 1883. Viaje a la provincia de Jujuy. Boletín del Instituto Geográfico Argentino V: 185-252.

CIPOLLETTI, M. 1984. Llamas y mulas, trueque y venta: el testimonio de un arriero puneño. Revista Andina 2: 513-538.

FLEITAS, M. y A. KINDGARD. 2006. Entre la legalidad y la proscripción. Políticas públicas y lucha obrera en Jujuy. 1918-1976, En Jujuy en la Historia. De la colonia al siglo XX, pp. 187-239. UNIHR, Universidad Nacional de Jujuy, San Salvador de Jujuy.

GIL MONTERO, R. 2006. La Puna: población, recursos y estrategias, En Jujuy en la Historia. De la colonia al siglo XX, pp. 373-401. UNIHR, Universidad Nacional de Jujuy, San Salvador de Jujuy.

GÖBEL, B. 2002. La arquitectura del pastoreo: uso del espacio y sistema de asentamiento en la Puna de Atacama (Susques). Estudios Atacameños 23: 53-76.

GOLOVANEVSKY, L. 2005. Mujeres y jóvenes en el mercado de trabajo. El caso del aglomerado San Salvador de Jujuy-Palapalá en los '9o, En Jujuy: arqueología, historia, economía sociedad. UNIHR, CEIC Jujuy, Universidad Nacional de Jujuy, San Salvador de Jujuy.

GORDILLO, G. 1995. Después de los ingenios: la mecanización de a zafra saltojujeña y sus efectos sobre los indígenas del chaco centro-occidental. Desarrollo Económico 35(137): 105-129.

JANOSCHKA, M. C. y REBORATTI. 2003. La movilidad de la población. En La Quebrada. Geografía, historia y ecología de la Quebrada de Humahuaca, C. Reboratti (Coord.), pp. 193-210. La Colmena, Buenos Aires.

KARASIK, G. 1985. Intercambio tradicional en la puna jujeña. RUNA XIV: 56-78.

KINDGARD, A. 2001. Alianzas y enfrentamientos en los orígenes del peronismo jujeño. Estructura de poder - Partidos políticos. UNIHR, UNJu, San Salvador de Jujuy.

KINDGARD, F. 1987. Mineros y Conflicto Social en los Andes Argentinos. En Dinámica de Estructuras Agrarias Regionales Investigaciones y Proyectos. Mimeo.

LAVANDAIO, E. 2004. Mina Aguilar, En Historia de la Minería Argentina, II, E. Lavandaio y E. Catalana (Eds.). SEGEMAR. Anales $\mathrm{N}^{\circ} 40$, Buenos Aires.

MASSEY, D., J. ARANGO, H. GRAEME, A. KOUAOUCHI, A. PELLERINO, y E. TAYLOR. 1998. Una evaluación de la teoría de la migración internacional: el caso de América del Norte. En Cruzando fronteras. Migraciones en el sistema mundial, G. Malgesini (Comp.). Icaria/Fundación Hogar del Empleado, Barcelona.

MEILLASOUX, C. 1985. Mujeres, graneros y capitales. Siglo XXI, México.

Ministerio de Planificación Federal, Inversión Pública y Servicios. 2008. Plan estratégico territorial. Buenos Aires: Subsecretaría de Planificación Territorial de la Inversión Pública. Ministerio de Planificación Federal, Inversión Pública y Servicios, Buenos Aires.

PAGLIARO, M. 1995. Análisis de la economía pastoril en una localidad de la puna jujeña: manejo del espacio y el riesgo productivo. Cuadernos del Instituto Nacional de Antropología y Pensamiento Latinoamericano 16: 103-119. 


\section{María Parodi y Alejandro Benedetti}

PANAIA, M. y S. APARICIO. 2000. Los orígenes de los asalariados en el NOA. En Trabajo y población en el Noroeste Argentino, M. Panaia, S. Aparicio y C. Zurita (Coords.), pp. 1-15. La Colmena, Buenos Aires.

REBORATTI, C. 1983. Peón golondrina: Cosecha y migraciones en la argentina, Cuaderno del CENEP 24:39.

1998. El Alto Bermejo, realidades y conflictos. La Colmena, Buenos Aires.

RUTLEDGE, I. 1987. Cambio agrario e integración. El Desarrollo del Capitalismo en Jujuy: 1550-1960. Proyecto ECIRA-Centro de Investigaciones en Ciencias Sociales, S. M. de Tucumán.

SALIZZI, E. 2014. Gran minería y transformaciones regionales en la Puna jujeña: el caso de la mina Aguilar (1936-1990). Estudios Sociales del NOA. Nueva Serie 13: 47-66.
TERUEL, A. 2006. Panorama económico y socio-demográfico en la larga duración (siglos XIX y XX). En Jujuy en la historia. De la colonia al siglo XX, pp. 295-345. UNIHR, Universidad Nacional de Jujuy, San Salvador de Jujuy.

TOMASI, J. 2005. Transformaciones urbanas y viviendas en Susques, Jujuy. Presentación en el Instituto de Arte Americano e Investigaciones Estéticas. Buenos Aires.

TRINCHERO, H. 2000. Los dominios del demonio. Civilización y barbarie en las fronteras de la Nación. El chaco central. Eudeba, Buenos Aires.

WHITEFORD, S. 1981. Workers from the North: plantations, Bolivian Labor, and the City in Northwest Argentina. The University of Texas Press, Austin. 